University of Louisville

ThinkIR: The University of Louisville's Institutional Repository

Electronic Theses and Dissertations

$12-2016$

\title{
Retinoic acid signaling regulates KRT5 independently of stem cell markers in submandibular salivary gland epithelium.
}

Timur Maratovich Abashev

University of Louisville

Follow this and additional works at: https://ir.library.louisville.edu/etd

Part of the Developmental Biology Commons

\section{Recommended Citation}

Abashev, Timur Maratovich, "Retinoic acid signaling regulates KRT5 independently of stem cell markers in submandibular salivary gland epithelium." (2016). Electronic Theses and Dissertations. Paper 2575.

https://doi.org/10.18297/etd/2575

This Master's Thesis is brought to you for free and open access by ThinkIR: The University of Louisville's Institutional Repository. It has been accepted for inclusion in Electronic Theses and Dissertations by an authorized administrator of ThinkIR: The University of Louisville's Institutional Repository. This title appears here courtesy of the author, who has retained all other copyrights. For more information, please contact thinkir@louisville.edu. 
RETINOIC ACID SIGNALING REGULATES KRT5 INDEPENDETLY OF STEM
CELL MARKERS IN SUBMANDIBULAR SALIVARY GLAND EPITHELIUM

Timur Maratovich Abashev

\author{
A Thesis \\ Submitted to the Faculty of the \\ School of Dentistry at the University of Louisville \\ In Partial Fulfillment of the Requirements \\ For the degree of
}

Master of Science in Oral Biology

Department of Oral Immunology and Infectious Diseases

University of Louisville

Louisville, Kentucky

December 2016 



\title{
RETINOIC ACID SIGNALING REGULATES KRT5 INDEPENDENTLY OF STEM CELL MARKERS IN SUBMANDIBULAR SALIVARY GLAND EPITHELIUM
}

\author{
By \\ Timur Abashev \\ Doctor of Stomatology., Moscow State Medical Stomatological University, \\ 2012
}

Thesis Approved on

November 22, 2016

By the following Thesis Committee:

Dr. Lisa Sandell. Ph. D.

Dr. Shuang Liang, Ph.D.

Dr. Douglas Darling, Ph.D. 


\section{ACKNOWLEDGMENTS}

I want to thank Deanna Buenger and Swetha Raja for their support and trust in me.

I want to thank Diana Wright for teaching me lab techniques and helping me to conduct my experiments. I want to thank Diana for helping to develop new procedures in the lab and enduring all the obstacles with me through this process.

I want to thank Dr. Melissa Meztler for helping me to perfect my experiments and properly interpret the results. Without Dr. Meztler's input, this study would not be at completion.

I want to thank my committee members Dr. Douglas Darling, Dr. Shuang Liang and Dr. Dennis Warner for their advice and support for my project. I want to thank them for encouraging me to learn more and to strive for perfection. In addition, I want to thank Dr. Darling as a program director for supporting me as a Masters student and guiding me towards my ultimate goal.

I want to sincerely thank my mentor Dr. Lisa Sandell for accepting me in her lab. I want to thank her for dedicating time and effort to teach me and give guidance through all my time in the Masters program at the University of Louisville. I want to thank Dr. Sandell for actively participating in my research at all stages. 
Moreover, I want to thank Dr. Sandell for helping me to see science from a different angle and broadening my view on research. I want to thank Dr. Sandell for believing in my potential as a scientist and supporting me in my all my endeavors. Thank you for helping me to adapt in the new country. It has been an honor to work under the supervision of such great researcher and teacher. The knowledge and experience I obtained in this program shaped me as an outstanding clinician and scientist and will help me with my future achievements.

Research in the Sandell laboratory is supported by R15 DE025960 and a Competitive Enhancement Grant from the University of Louisville EVPRI. MAM was supported by F31 DE022679. The Microscopy Suite at the Cardiovascular Innovation Institute in Louisville, KY is supported by GM103507. 


\begin{abstract}
RETINOIC ACID SIGNALING REGULATES KRT5 INDEPENDENTLY OF STEM

CELL MARKERS IN SUBMANDIBULAR SALIVARY GLAND EPITHELIUM
\end{abstract}

Timur Abashev

November 22, 2016

Vitamin A metabolism, which produces the signaling molecule Retinoic Acid (RA), has been demonstrated to be important for growth and branching morphogenesis of mammalian embryonic salivary gland epithelium. However, it is not known whether RA functions directly within epithelial cells or in associated tissues that influence morphogenesis of salivary epithelium. Moreover, downstream targets of RA transcriptional regulation have not been identified. Here we show that canonical RA signaling occurs in multiple tissues of embryonic mouse salivary glands, including epithelium, associated parasympathetic ganglion neurons, and non-neuronal mesenchyme. By culturing epithelium explants in isolation from other tissues we demonstrate that RA influences epithelial morphogenesis by direct action in that tissue. Moreover, we demonstrate that inhibition of RA signaling represses FGF10 signaling and upregulates expression of the basal epithelial keratins $K r t 5$ and $K r t 14$. Importantly, we show that the stem cell gene Kit is regulated inversely from 
$K r t 5 / K r t 14$ by RA signaling. Thus, expression of $K r t 5$ and $K r t 14$ are independent of stem cell character in this context. These data suggest that RA or chemical inhibitors of RA signaling could potentially be used for modulating growth and differentiation of epithelial stem cells for the purpose of re-populating damaged glands or generating bioengineered organs 


\section{TABLE OF CONTENTS}

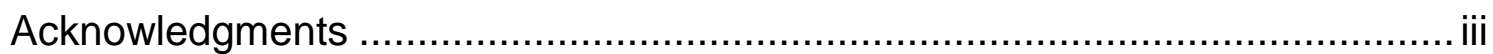

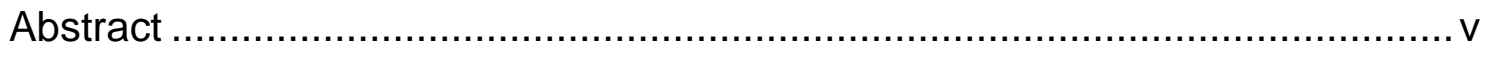

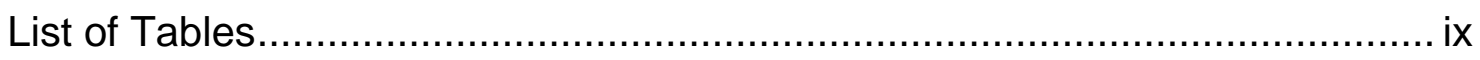

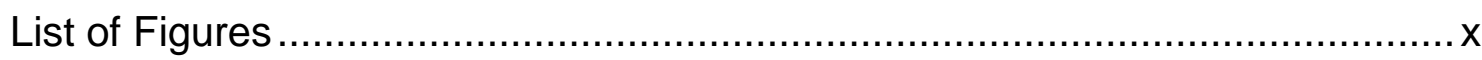

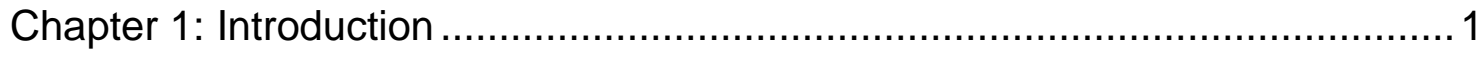

1.1 Salivary gland overview ......................................................... 1

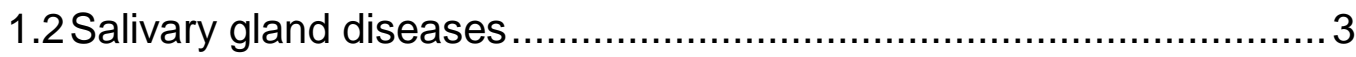

1.3 Treatment of salivary gland diseases .......................................... 4

1.4 Development of salivary glands .................................................... 5

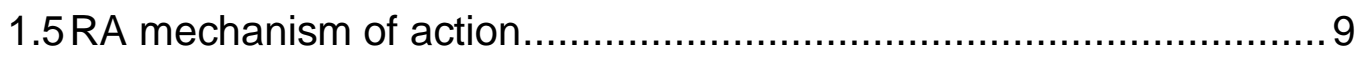

Chapter 2: Materials and Methods........................................................... 13

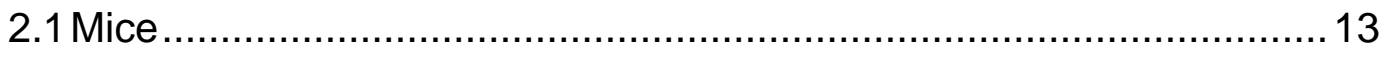

2.2SMG whole gland ex vivo culture .............................................. 13

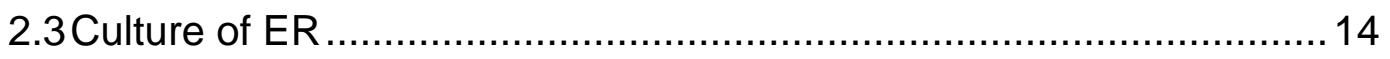

2.4 Stain for RARE-LacZ reporter activity........................................... 16

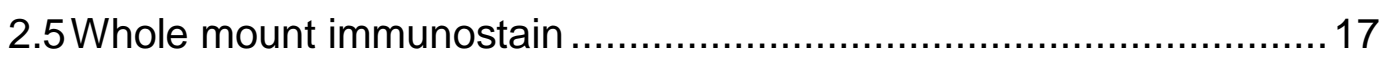

2.6 Frozen section immunostain....................................................... 18

2.7 Quantification of mRNA by qPCR ............................................ 19

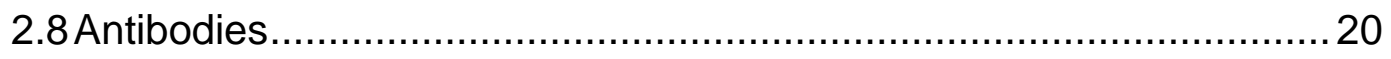

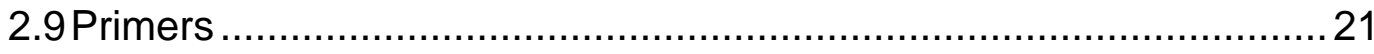




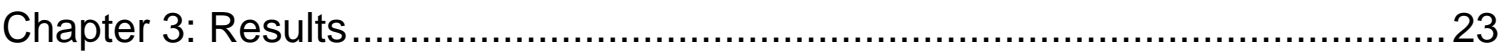

3.1 RA signaling occurs in multiple tissues of developing SMG.............23

3.2 Standard curve Verification of qPCR primers in cultured ER .............34

3.3 Inhibition of RA signaling impairs branching morphogenesis and

FGF10 activity in cultured ER ........................................................ 42

3.4 Inhibition of RA signaling leads to downregulation of proliferation

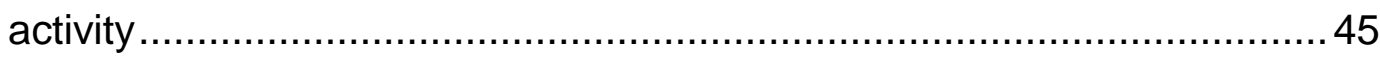

3.5 Block of RA signaling upregulates expression of KRT5 ................... 48 3.6 Addition of RA signaling impairs branching morphogenesis in cultured

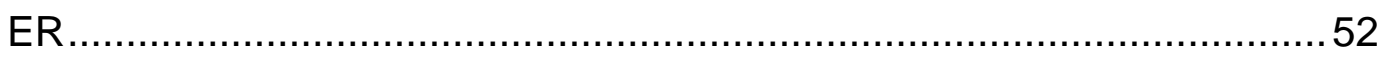
3.7 Block of RA signaling coordinately upregulates expression of $K r t 5$ and

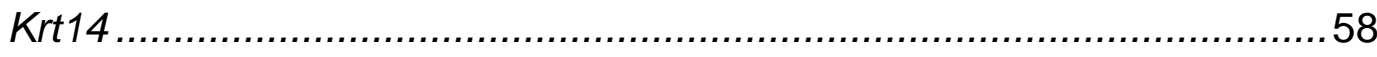

3.8 Stem cell marker Kit is regulated inversely to $K r t 5 / K r t 14$ by RA

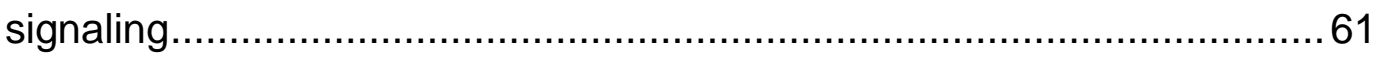

3.9 Bioinformatic analysis of RAR and RXR binding motifs near keratin

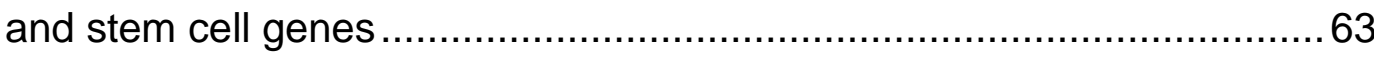

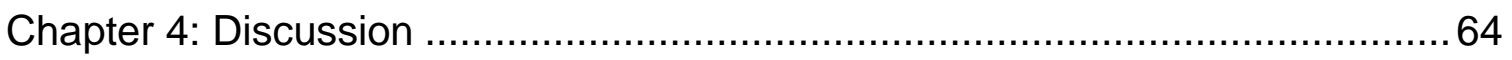

Chapter 5: Summary and Conclusions ….................................................... 73

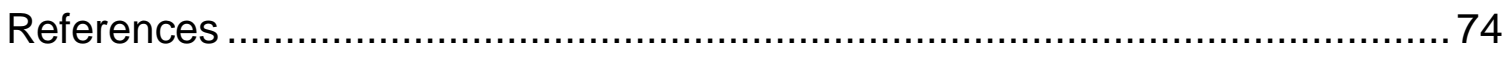

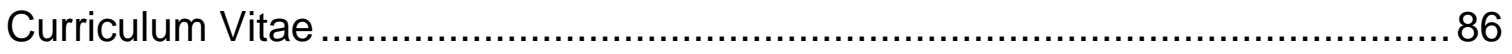




\section{LIST OF TABLES}

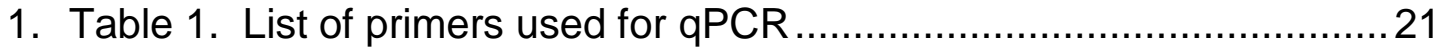

2. Table 2. Number of RA positive cells in E13.5 and E14.5 SMG .............28

3. Table3. Branch number Control RA and statistical verification ...............56 


\section{LIST OF FIGURES}

1. Figure1: Schematic representation of stages of salivary gland

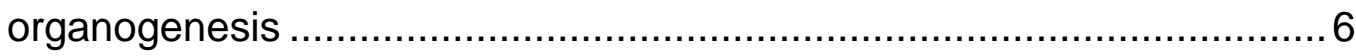

2. Figure 2. RA regulates gene transcription.......................................... 10

3. Figure 3. RA signaling occurs in multiple tissues of developing SMG ....26

4. Figure4: RA signaling localization and persistence in SMG tissues in ex vivo culture.

5. Figure. 5. Mosaic RA signaling in ducts and endbuds persists during culture

6. Figure 6: Gapdh and Krt5 primer efficiency standard curve and date of verification

7. Figure 7: Krt19 and Sox2 primer efficiency standard curve and date of verification

8. Figure 8: Klf4 and Krt8 primer efficiency standard curve and date of verification

9. Figure 9: Myc and Actb primer efficiency standard curve and date of verification

10. Figure 10: Etv5 and Krt14 primer efficiency standard curve and date of verification.

11. Figure 11: Kit and Top2a primer efficiency standard curve and date of verification. 
12. Figure 12: Mki67 primer efficiency standard curve and date of verification 41

13. Figure 13. RA signaling regulates developmental growth of epithelium by direct action in epithelial tissue ......................................................... 42

14. Figure14: Expression of proliferation markers Ki67 and Top2a .............. 47

15. Figure 15. Inhibition of RA signaling in cultured ER upregulates ductal

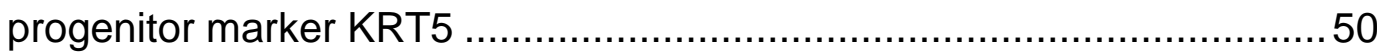

16. Figure16: Test of different concentrations of RA on ER cultured for 1 day 54

17. Figure17: Isolated epithelia cultured with addition of retinoic acid or BMS 493 cultured for 2 days 55

18. Figure18: Immunostaining of ER cultured for 2 days on control medium, or

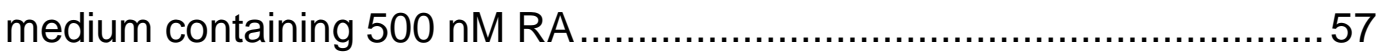

19. Figure 19. Inhibition of RA signaling upregulates expression of $K r t 5$ and

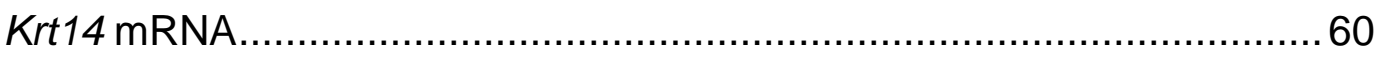

20. Figure 20. Inhibition of RA signaling downregulates expression of stem

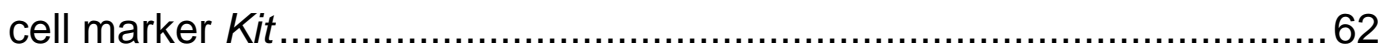




\section{CHAPTER 1}

\section{INTRODUCTION}

\subsection{Salivary gland overview}

The oro-maxillofacial area is a complex part of the human body that serves many functions. It is important for initial food processing, communication, aesthetics and many other aspects of life. The oro-maxillary region hosts specific unique organs. Among these are salivary glands, which play significant roles in physiology. Some salivary gland functions are important for local oral health. For instance, salivary glands are essential for maintenance of local immunity in the oral cavity, facilitation of food processing, and digestion. Salivary glands also play role in general health and physiology. For example, they filter and excrete metabolites from the systemic blood to help rid the body of toxins. The main function of salivary glands is a production of a specific secretion called saliva. Saliva is a crucial component of an oral cavity. Saliva determines $\mathrm{pH}$ of an oral cavity, controls mineralization of teeth, facilitates food digestion and vocalization and plays a variety of other functions.

Salivary glands are represented by two main groups anatomically: major salivary glands and minor salivary glands. Minor salivary glands are scattered through mucosal tissue of the respiratory tract and the upper digestive tract, primarily within the tongue and lips of the oral cavity. Major salivary glands are positioned 
in oro-facial area in close proximity to the oral cavity. The major salivary glands are represented by three pairs: the parotid, the submandibular, and the sublingual salivary glands.

The parotid salivary gland pair is located in masseter-retromandibular area and in the upper portion of the neck. The main ducts of the parotid glands open near upper into the oral cavity near the second molar on the mucosa of the cheek. In humans, the parotid glands are the largest salivary gland pair. Parotid glands secrete saliva enriched in serous, proteinous components. The second pair of major salivary glands is the submandibular salivary gland pair. The submandibular salivary glands (SMG) are positioned in the submandibular area medial to a mandible, with one portion on top of the mylohyoid muscle, and another underneath. The main ducts of the SMG open under the tongue. SMG produce a mixed type of saliva, with both serous and mucous components. The third type of major salivary glands are called sublingual gland, located under the tongue. The main ducts of the sublingual glands also open under the tongue, and sometimes the ducts of the sublingual glands and the SMG fuse and open as one. Sublingual glands mainly produce mucous saliva.

Salivary glands are important for human health. Loss of salivary gland function, which occurs frequently in patients suffering from the autoimmune condition Sjogren's syndrome, or in cancer patients treated with radiation to the head and neck, has devastating consequences for quality of life. Thus, knowledge of salivary gland biology is an important research goal. 


\subsection{Salivary gland diseases}

Diseases of salivary gland create a significant human healthcare issue. The condition when salivary glands do not produce enough saliva is called xerostomia.There are several reasons that lead to this condition. In The United States cancers of the head and neck are diagnosed at a rate of approximately 50,000 new cases each year (Altekruse et al., 2010), and treatment of head and neck cancers, using radiation therapy of the, carries a significant risk of damaging salivary glands (Liu, C. C et al., 2011, Vergeer, M. R. et al., 2009). Salivary glands health and function can also be compromised as a result of the condition called Sjogren's syndrome. It is a common systemic autoimmune disorder, and as much as $3 \%$ of people in their 70 s can suffer from this condition(Baldini, C. et al., 2012, Haugen, A. J. et al., 2008). The syndrome creates with significant healthcare costs and substantially affects the quality of life (Strömbeck, B. et al., 2000).

Treatment of salivary gland diseases has a great importance in order to help patients that suffer from salivary gland diseases and maintenance of oral health. Research of "salivary gland morphogenesis and structure" has been identified as one of the priorities of oral health research. Restoration of salivary production is the long-term goal of this research and it is aimed at the patients with xerostomia. This can be achieved via approaches such as transplantation of salivary gland 
stem cells or bioengineered organs (Joraku, A. et al., 2007, Lombaert, I. M. et al., 2008, Holmberg, K. V. et al., 2014, Nguyen, T. T. et al., 2013).

\subsection{Treatment of salivary gland diseases.}

Diseases of salivary glands are detrimental for patients. Current treatments for xerostomia include drugs that increase salivation, and artificial salivary substitutes. These treatment options only alleviate symptoms or force residual salivary gland tissue to work over its limit. They do not help to restore or regenerate salivary glands. Therefore, new approaches aimed at healing and repairmen of glandular tissue must be created. Two new promising treatment modalities are stem cell therapy and organ bioengineering. These options hold potential for repair of damaged glands and also for replacement of completely nonfunctional organs. Some progress toward creating functional bioengineered salivary glands has been made. Salivary glands were generated from mouse embryonic salivary gland cells, and the bioengineered glands were implanted into experimental animals (Ogawa et al., 2013). The bioengineered organs were able to produce a secretion; however, the quality of the saliva was not completely comparable with natural analog. Therefore, more precise understanding of embryonic development and salivary gland formation is needed.

\subsection{Development of salivary glands}

Murine salivary glands are similar to human salivary glands anatomically, physiologically, and genetically, therefore mouse is a good model to study salivary glands. 
A well-studied model of salivary gland organogenesis is SMG growth and development in the mouse. SMG develop through certain stages. Formation of SMG in mice starts at embryonic day 11.5 (E11.5) as a thickening of oral epithelium on each side of the base of tongue (Fig. 1A). By the E12.5 stage of development, epithelium dives into the surrounding mesenchyme and forms a structure called initial bud (Fig. 1B). As gland development progresses, the initial bud undergoes processes that are called clefting and branching. As soon as the first round of clefting is completed, the SMG has a 3-5 bud structure (Fig. 1C). This phase is called the pseudo-glandular stage. The next important stage in SMG formation is an establishment of initial ducts. By day E15.5 the terminal cells of endbuds start to differentiate into specialized secretory saliva-producing cells (Fig. 1D). As morphogenesis progresses, a gland undergoes sequential rounds of clefting and branching, forming a complex network of ducts acini with end buds, which empty into bigger diameter ducts and eventually into a main excretory duct that opens into the oral cavity. Formation of SMG is largely completed by embryonic day E17.5 (Fig. 1E), but differentiation and maturation of cells continue for several weeks postnatally. 


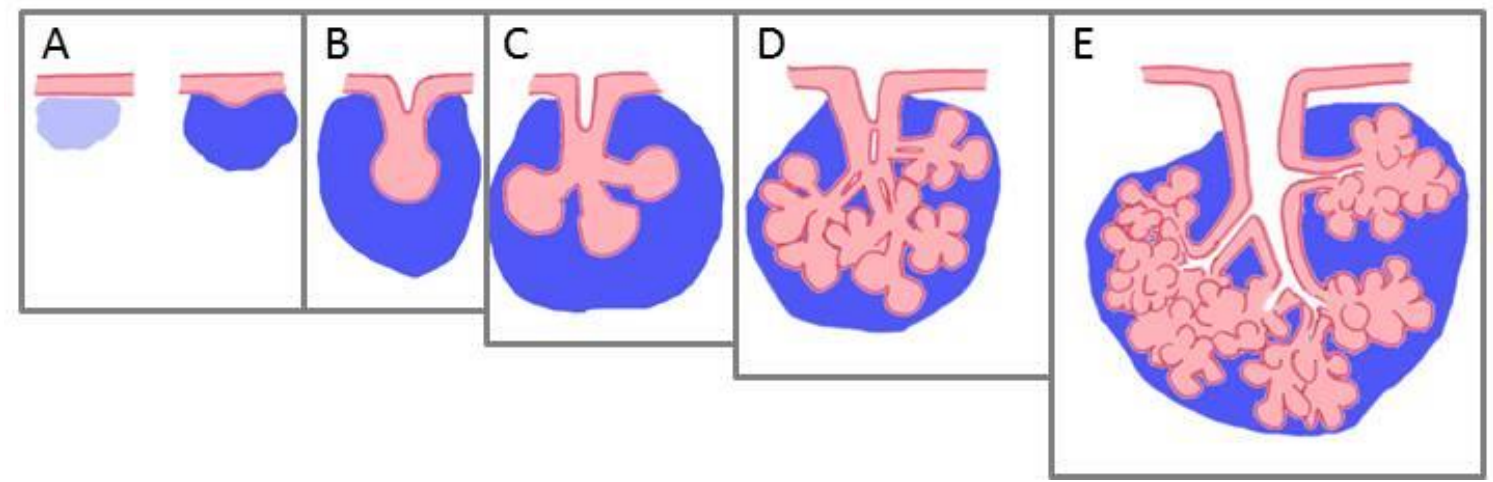

Figure 1: Schematic representation of stages of salivary gland organogenesis.

(A) initiation of the SMG thickening of oral epithelium. (B) Initial bud stage. (C)

Pseudo-glandular stage. (D) Initial duct formation (E) Formed salivary gland 
Previous research has highlighted the importance of interactions between different tissues of developing salivary glands during SMG morphogenesis. For example, at early stages of development, interactions between oral epithelium and underlying mesenchyme are critical for salivary gland formation (Kratochwil, 1969; Wells et al., 2013). At later stages of morphogenesis, neurons of the submandibular parasympathetic ganglion stimulate growth, branching, and tubulogenesis of gland epithelium (Knox et al., 2010; Nedvetsky et al., 2014). Studies of mutant mice and experiments with tissue explants cultured ex vivo have demonstrated that signaling by growth factor FGF10 via its receptor FGFR2b is critical for growth and branching morphogenesis of embryonic salivary epithelium (De Moerlooze et al., 2000; Entesarian et al., 2005; Jaskoll et al., 2005; Ohuchi et al., 2000; Steinberg et al., 2005).

Although, signaling molecules are essential for normal development of salivary gland epithelium extracellular matrix (ECM) also significantly influences the process. Among many ECM molecules, Heparan Sulfate is considered to be the most important. This ECM molecule increases the affinity of FGF10 to its receptor and possibly other growth factors (Makarenkova et al., 2009; Patel et al., 2016). Therefore, it has a direct effect on branching morphogenesis of salivary gland epithelium.

A major goal of salivary gland research is to identify the molecular regulation of epithelial progenitor cells that could contribute to the regeneration of damaged glands or could be used to direct differentiation of stem cells to bioengineer replacement salivary epithelium. One pair of molecules proposed to 
mark salivary gland progenitor cells are the intermediate filament proteins cytokeratin 5 (KRT5) and KRT14 (Knox et al., 2010; Lombaert et al., 2011). Krt5 is expressed in the basal layer of developing SMG epithelium. Lineage tracing of cells expressing Krt5 early demonstrated that these cells give rise to most of the SMG epithelium, suggesting Krt5 marks multipotent cells with progenitor character (Knox et al., 2010). In addition to marking progenitor cells of salivary glands, KRT5 and KRT14 are present in basal progenitors cells in other epithelial organs, including trachea (Rock et al., 2009), prostate (Hudson et al., 2001), bladder (Colopy et al., 2014), and lung (Zuo et al., 2015). Although Krt5 expression is associated with progenitor character in salivary glands, the recent discovery that SMG acinar cells regenerate by self-duplication (Aure et al., 2015) demonstrated that acinar epithelium does not renew from ductal $K r t 5+$ cells (Aure et al., 2015).

An additional factor that is present in stem cells or progenitor cells of salivary epithelium is the receptor tyrosine kinase KIT. KIT is present is stem or progenitor cells of the hematopoietic system and many other tissues and organs (Broudy, 1997; Ogawa et al., 1991). In salivary glands, KIT+ epithelial progenitor cells are able to regenerate irradiated glands (Lombaert et al., 2008; Nanduri et al., 2013). 


\subsection{RA mechanism of action}

RA, the active metabolite of Vitamin A (all-trans-retinol), is a small lipid-soluble molecule that regulates many aspects of embryogenesis and adult health (reviewed in (Clagett-Dame and Knutson, 2011)). Knowledge about how RA and related molecules may regulate embryonic morphogenesis of specific tissue types is needed for a basic understanding of developmental biology and because retinoids hold an obvious potential to be used pharmacologically. Canonical RA signaling occurs through a family of ligand-responsive nuclear receptors known as retinoic acid receptors (RAR), which bind to regulatory DNA elements known as RA response elements (Fig. 2). RAR may work as heterodimers with related nuclear transcription factors known as RXR(Mark M. et al.,2009). However, RXR can interact with other nuclear receptors independently of RAR(Tanoury, Z. et

al.,2013) Although canonical RA signaling through RAR has historically been considered primarily in terms of ligand-dependent activation, emerging evidence indicates that ligand-dependent repression by RAR is a common mechanism of RA-mediated gene regulation (Liu et al., 2014).

Analysis of $K r t 5$ and $K r t 14$ cis-regulatory elements indicates that RA signaling represses $K r t 5$ expression in epidermal epithelial cells. RAR regulate $K r t 5$ expression by binding to negative RA response elements upstream of the Krt5 promoter (Jho et al., 2001; Ohtsuki et al., 1992; Radoja et al., 1997; Tomic et al., 1990). In that context, ligand-occupied RAR suppress expression while unliganded RAR promote expression of Krt5 (Tomic-Canic et al., 1996). 


\section{Vitamin A is converted into active form RA}
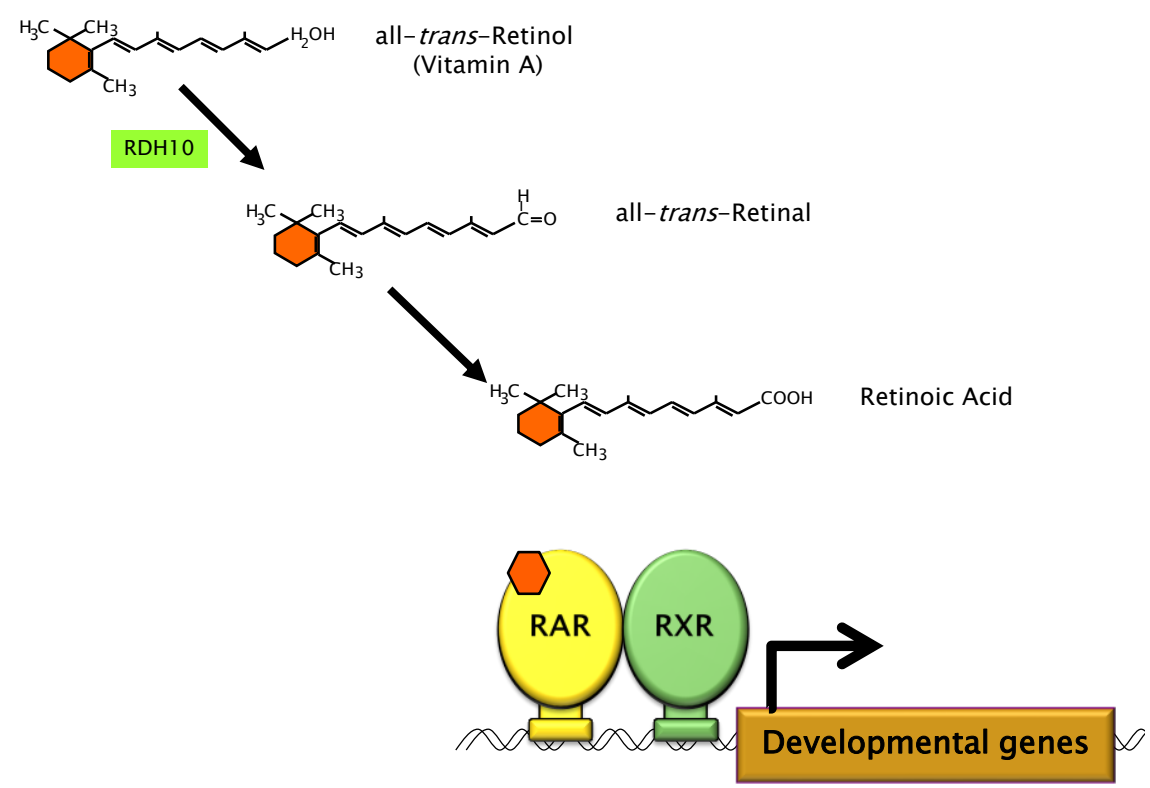

Figure 2. RA regulates gene transcription. RA is the active metabolite of Vitamin A. RA acts as a ligand to RAR transcription factors. RA is capable of regulation of transcription of developmental genes. 
We recently identified that $R A$ is a critical regulator of mammalian salivary gland morphogenesis, and that blockage of RA signaling disrupts growth and branching morphogenesis of salivary epithelium (Wright et al., 2015). Our initial study was based on analyses of RA deficient mouse embryos and ex vivo culture of the whole SMG. As such, it was not possible to discern whether RA influences epithelial growth and branching by direct action in epithelial cells, or if RA influences epithelial morphogenesis indirectly by regulation of a different tissue that is needed for epithelium development. Moreover, downstream target genes of RA transcriptional regulation have not investigated in developing salivary gland.

Here we report that RA signaling occurs in epithelial, neuronal, and mesenchymal tissues of the developing mouse SMG. By culturing isolated epithelial rudiments (ER) ex vivo in the presence or absence of a chemical RAR inhibitor, we show that RA signaling regulates growth and branching of epithelial tissue directly. We identify that the RA signaling pathway positively regulates FGF10 signaling activity in cultured SMG epithelia. We further demonstrate that inhibition of RA signal in cultured ER is associated with dramatic transcriptional upregulation of $K r t 5$ and $K r t 14$. Lastly, we demonstrate that the de-repression of Krt5 following RA signal inhibition does not correlate with altered expression of other salivary keratin genes or with stem cell markers. These findings demonstrate that RA signaling modulates differentiation of salivary epithelium by direct action within the epithelial cells and that RA negatively regulates 
expression of $K r t 5$ and $K r t 14$, but positively influences FGF10 signaling and Kit expression. 


\section{CHAPTER 2}

\section{MATERIALS AND METHODS}

\subsection{Mice}

FVB/NJ mice were obtained from Jackson laboratories. FVB/NJ embryos were used for ER culture experiments and for qPCR quantitation of gene expression. RARE-lacZ reporter mice (Rossant et al., 1991), were obtained from Jackson laboratories (official name, Tg(RARE-Hspa1b/lacZ)12Jrt). RARE lacZ embryos were used for immunostain analysis of RA signaling. The day of the vaginal plug was considered E0.5. All experiments involving mice were performed in accordance with a protocol approved by the Institutional Animal Care and Use Committee at the University of Louisville.

\subsection{SMG whole gland ex vivo culture}

SMG gland rudiments containing submandibular and sublingual salivary glands were dissected from mouse embryos at E13.5. Isolated SMG were cultured at the medium-air/interface on filter disks (Whatman Nucleopore, $13 \mathrm{~mm}, 0.1 \mu \mathrm{m}$ pore size: VWR) supported at a surface of the medium by gaskets made from Syglard elastomer. Medium was DMEM/F12 with $100 \mathrm{U} / \mathrm{ml}$ penicillin, $100 \mu \mathrm{g} / \mathrm{ml}$ streptomycin, $150 \mu \mathrm{g} / \mathrm{mlVitamin} \mathrm{C}$, and $50 \mu \mathrm{g} / \mathrm{ml}$ transferrin. Isolated glands were cultured in a humidified incubator at 
$37{ }^{\circ} \mathrm{C}$ with $5 \% \mathrm{CO} 2 / 95 \%$ air. For experimental treatment with pan-RAR inhibitor, a stock solution of $1 \mathrm{mM}$ BMS 493 (Tocris, \#3509) in DMSO was added to the medium for a final concentration of $2 \mu \mathrm{M}$ BMS 493 in the culture medium. An equivalent volume of DMSO was added to the medium for control samples.

\subsection{Culture of ER}

The medium used for dissection and washes was DMEM/F12 containing HEPES (HyClone SH30126.01). The medium used for culture was DMEM/F12 without HEPES (HyClone SH30271.01) plus $50 \mu \mathrm{g} / \mathrm{ml}$ transferrin, $150 \mu \mathrm{g} / \mathrm{ml}$ ascorbic acid, Penicillin/Streptomycin, $500 \mathrm{ng} / \mathrm{ml}$ recombinant mouse FGF 10 (RD Systems 6224-FG-025), and $500 \mathrm{ng} / \mathrm{ml}$ Heparan sulfate proteoglycan (SigmaAldrich H4777).

ER culture methods were based on a protocol described in (Steinberg et al., 2005). E13.5 SMG with 3-6 endbuds were dissected under a stereomicroscope in dissection medium. Once isolated, SMG were treated with dispase I (Sigma-Aldrich D4818), $1.6 \mathrm{U} / \mathrm{ml}$ in phosphate buffered saline (PBS), to loosen epithelium from mesenchyme. Dispase I incubation was performed in a well of a glass staining plate for $17 \mathrm{~min}$ in a humidified chamber $37^{\circ} \mathrm{C}, 5 \% \mathrm{CO}_{2}$. After dispase I treatment, dispase was inactivated by washing specimens 3 times in $7.5 \%$ BSA in dissection medium. ER were then separated from surrounding mesenchyme using fine tip forceps and were washed in dissection medium to remove BSA. Specimens were cultured inside a $15 \mu \mathrm{l}$ drop of growth factor- 
reduced Matrigel (Corning catalog number 356230). Prior to each experiment, an aliquot of Matrigel was thawed at $4^{\circ} \mathrm{C}$ overnight, then diluted $1: 1$ in dissection medium ( $4 \mathrm{mg} / \mathrm{ml}$ final). At the time of plating a $15 \mu$ drop of Matrigel was placed on top of a $13 \mathrm{~mm}$ diameter Nuclepore Track-Etch membrane filter, pore size $0.1 \mu \mathrm{m}$ (Whatman, 110405). Filters were placed over $100 \mu \mathrm{l}$ of culture medium supported by a silicone culture well gasket (Grace Biolabs CW-4R-1.0) in a plastic petri dish, with a small petri lid filled with $\mathrm{H}_{2} \mathrm{O}$ to ensure humidity within the culture dish. Specimens were cultured at 3-8 ER/filter. ER were cultured 48 hours in a humidified incubator at $37^{\circ} \mathrm{C}$ with $5 \% \mathrm{CO} / 95 \%$ air. Cultures were fed daily by adding fresh culture medium to an empty well of the culture well gasket and moving filter.

For inhibition of canonical RA signaling the pan-RAR inverse agonist BMS 493 (Tocris, \#3509) was used. For each experiment, a fresh BMS 493 stock solution $5 \mathrm{mM}$ in DMSO was prepared. The BMS 493 stock solution was then diluted in culture medium for a final concentration of $5 \mu \mathrm{M}$. For control samples, an equivalent volume of DMSO was added to culture medium.

Specimens were imaged with transmitted light at beginning and end of the culture period on using a Leica M165 stereomicroscope with Leica imaging software. Branching morphogenesis and growth of ER specimens were assessed by counting of endbuds and by quantification of a visible area using ImageJ software. The significance of the difference in a number of endbuds was calculated using Student's T-test. 


\subsection{Stain for RARE-lacZ reporter activity}

RARE-lacZ or Rdh $10^{\beta g e o}$ reporter $\beta$-galactosidase activity was assayed by fixing whole embryo or tissue specimens in $2 \%$ Paraformaldehyde $/ 0.2 \%$ glutaraldehyde for 45-90 min on ice. Following fixation, specimens were rinsed and incubated 30 min at room temperature in Rinse Solution A: 5 mM EGTA/2 mM MgCl2/PBS pH 7.3 (lab mixed or purchased from Millipore). Specimens were then rinsed and incubated 15 minutes at $37^{\circ} \mathrm{C}$ in pre-warmed Rinse Solution B: 2 mM MgCl2/0.01\% Sodium deoxycholate/0.02\% NP40/PBS pH 7.3 (lab mixed or purchased from Millipore). Stain Base solution: $0.5 \mathrm{mM} \mathrm{K}_{3} \mathrm{Fe}\left(\mathrm{CN}_{16} / 0.5 \mathrm{mM}\right.$ $\mathrm{K}_{4} \mathrm{Fe}\left(\mathrm{CN}_{6} / 2 \mathrm{mM} \mathrm{MgCl} / 2 / 0.01 \%\right.$ Sodium deoxycholate/0.02\% NP40/PBS pH 7.3 (lab mixed or purchased from Millipore), was pre-warmed to $37^{\circ} \mathrm{C}$ prior to addition of the reaction substrate X-gal. When specimens were fixed, rinsed, and ready to be stained, X-gal (Sigma-Aldrich B4252, suspended at $40 \mathrm{mg} / \mathrm{ml}$ in Dimethyl Formamide) was added to Stain Base Solution to a final concentration of $1 \mathrm{mg} / \mathrm{ml}$. Specimens were incubated in stain solution overnight at $37^{\circ} \mathrm{C}$ in the dark. After staining, specimens were post-fixed in $4 \%$ Paraformaldehyde overnight at $4{ }^{\circ} \mathrm{C}$. 


\subsection{Whole mount immunostain}

The whole mount cultured ER specimens were fixed on filters with $4 \%$ formaldehyde at room temperature for $1 \mathrm{hr}$, then made permeable by incubation in $0.1 \%$ Triton in PBS. After permeabilization, specimens were blocked in $0.1 \mathrm{M}$ Tris $\mathrm{pH} 7.5,0.15 \mathrm{M} \mathrm{NaCl}$ with blocking reagent (Perkin Elmer FP1020). Primary antibody hybridization was performed in blocking solution overnight $4^{\circ} \mathrm{C}$.

Following primary antibody incubation, specimens were washed $5 \times 1 \mathrm{hr}$ in PBS at room temperature. Hybridization with fluorescent secondary antibodies was performed in blocking solution overnight at $4_{0} \mathrm{C}$. After secondary antibody hybridization specimens were washed $3 \times 20 \mathrm{~min}$ in PBS. To aid in finding tissues during confocal microscopy specimens were stained with DAPI (10nM, 10 min) and washed in PBS. After staining ER specimens were post-fixed in 4\% formaldehyde for $45 \mathrm{~min}$ at room temperature. All steps were performed with gentle rocking. For confocal imaging, stained ER specimens on filters were placed in a depression slide in PBS, covered with a coverslip affixed with vacuum grease, and imaged with an Olympus MPE FV1000 confocal microscope. 


\subsection{Frozen section immunostain}

Embryonic heads were collected at E13.5 and E14.5 stages of

development and fixed overnight in $4 \%$ formaldehyde at $4{ }^{\circ} \mathrm{C}$. Following fixation, samples were equilibrated in $30 \%$ sucrose overnight at $4^{\circ} \mathrm{C}$. Samples were embedded in OCT compound and stored at $-80^{\circ} \mathrm{C}$. Tissues were cut at $12 \mu \mathrm{m}$ thickness, vacuum dried $1 \mathrm{hr}$, and stored at $-80^{\circ} \mathrm{C}$. For staining, 1 sections were enclosed with a hydrophobic barrier using a PAP pen and washed for 5 min in $0.1 \%$ Tween 20 in PBS (PBT). Blocking was performed in blocking solution (as described for whole mount immunostain) for $1 \mathrm{~h}$ at room temperature. Primary antibodies were hybridized overnight at $4{ }^{\circ} \mathrm{C}$ in a humidified chamber in blocking solution. Following incubation with primary antibodies, slides were washed $3 \times 10$ min in PBT. Secondary antibody hybridization was performed for 1 $\mathrm{hr}$ at room temperature in blocking solution. Unbound secondary antibody was removed by washing $3 \times 10 \mathrm{~min}$ in PBT. Nuclei were stained with DAPI (10nM, 10 min), followed by a final was in PBT. Stained slides were mounted with Prolong Gold mounting medium (ThermoFisher P36930). Stained frozen sections were imaged on a Zeiss Axiolmager.A1. 


\subsection{Quantification of mRNA by qPCR}

For gene expression analysis ER were cultured 6-8 specimens per filter. Following culture, ER specimens were recovered from Matrigel by incubating with Corning Cell Recovery solution (Corning 354253 ) for $1 \mathrm{hr}$ on wet ice at $4^{\circ} \mathrm{C}$ with gentle shaking. ER were then washed twice with ice-cold PBS by spinning at 200G for 1 min. Total RNA was extracted with RNeasy Micro Kit (Qiagen 74004). DNA was removed by on-column DNase I digestion (Qiagen 79254). RNA was reverse transcribed to cDNA using random hexamers and the SuperScript III First-Strand Synthesis System (Invitrogen 18080-051). SYBRgreen qPCR was performed using SYBR Select Master Mix (Applied Biosystems 4472908). For each qPCR reaction, $100 \mathrm{ng}$ of cDNA was used as a template. Data represent the average of 3 independent culture experiments with 6-8 ER/condition. Each sample was run as 3 technical replicates, except $K r t 5$, which was run as 6 technical replicates. To identify a suitable control gene for normalization of mRNA levels in this experimental context Gapdh and Actb expression were assessed in control and BMS-treated samples to determine if an expression of either gene varied relative to the other. No difference was observed between Gapdh and Actb expression patterns, demonstrating that either gene could be used as an appropriate normalization control for ER cultured on control or BMS 493 medium. Gapdh was therefore used for normalization of gene expression. All primers were validated for efficiency between $90 \%-110 \%$. Data was evaluated by the $2^{-\Delta \Delta C T}$ method (Livak and 
Schmittgen, 2001). Significance was evaluated by two-tailed Student's T-test assuming unequal variance.

\subsection{Antibodies}

Primary antibodies used were:

anti- $\beta$-glactosidase (Abcam ab9361) 1:500, anti-E-cadherin (BD Biosciences \#610182) 1:50, anti-Neuronal Class III $\beta$-Tubulin (Covance, PRB0435-P) 1:1000, anti-Cytokeratin 5, (Abcam ab24647)1:1000.

anti-Cytokeratin-8 (DSHB TROMA-I)1:50.

Fluorescently conjugated secondary antibodies, each used at 1:300 were:

Alexafluor 488, AlexaFluor 546, AlexaFluor 660 (Invitrogen), or Dynalight 488 (Abcam). 


\subsection{Primers}

Many primers were identified using Primer Bank Database (Wang et al., 2012).

Table 1. List of primers used for qPCR

\begin{tabular}{|l|l|l|}
\hline Gene & Forward primer & Reverse primer \\
\hline Actb & GGCTGTATTCCCCTCCATCG & CCAGTTGGTAACAATGCCATGT \\
\hline Etv5 & TCAGTCTGATAACTTGGTGCTTC & GGCTTCCTATCGTAGGCACAA \\
\hline Gapdh & ACAGTCCATGCCATCACTGCC & GCCTGCTTCACCACCTTCTTG \\
\hline Kit & TCATCGAGTGTGATGGGAAA & GGTGACTTGTTTCAGGCACA \\
\hline Klf4 & GTGCCCCGACTAACCGTTG & GTCGTTGAACTCCTCGGTCT \\
\hline Krt5 & TCCAGTGTGTCCTTCCGAAGT & TGCCTCCGCCAGAACTGTA \\
\hline Krt8 & TCCATCAGGGTGACTCAGAAA & CCAGCTTCAAGGGGCTCAA \\
\hline Krt14 & AGCGGCAAGAGTGAGATTTCT & CCTCCAGGTTATTCTCCAGGG \\
\hline Krt19 & GGGGGTTCAGTACGCATTGG & GAGGACGAGGTCACGAAGC \\
\hline Mki67 & ATCATTGACCGCTCCTTTAGGT & GCTCGCCTTGATGGTTCCT \\
\hline Myc & ATGCCCCTCAACGTGAACTTC & CGCAACATAGGATGGAGAGCA \\
\hline Sox2 & GCGGAGTGGAAACTTTTGTCC & CGGGAAGCGTGTACTTATCCTT \\
\hline Top2a & CAACTGGAACATATACTGCTCCG & GGGTCCCTTTGTTTGTTATCAGC \\
\hline
\end{tabular}




\subsection{Statistical Analysis}

Statistical analysis was used in order to determine whether there was a significant difference between experimental groups. Student T-tests were completed (using Microsoft Excel software) to compare epithelium of cultured ER in control and treatment groups. We compared area, a number of buds and mRNA expression levels. This method was used to verify significant differences between ER in control group and BMS 493 treated group. Additional analysis was made to quantify a number of buds between control and RA treated group. Graphs and histograms were created using the same software. 


\section{CHAPTER 3}

\section{RESULTS}

\subsection{Identification of RA positive cells in murine SMG using in vivo and in vitro models.}

In order to investigate the precise distribution of active RA signaling in developing SMG tissues, we performed immunostaining on frontal sections of embryos carrying the RARE-lacZ transgenic reporter (Rossant et al., 1991). This reporter expresses LacZ encoding $\beta$-galactosidase in response to canonical RA signaling through RAR. In embryos carrying this reporter, staining for $\beta$ galactosidase reveals RA signaling activity.

\section{RA activity in vivo}

At E13.5 we observed strong RA signaling in individual cells of the developing SMG (Fig. 3 A-F). Co-staining for KRT-8, which is weakly expressed in the epithelium at this stage, reveals that cells positive for RA signaling are within the epithelial tissues (Fig. 3 A, B, within white dotted outline). RA signalpositive cells appear in a random mosaic pattern within the KRT8-positive epithelium. Counting the RA-positive cells in comparison to the number of DAPIpositive nuclei of the epithelium indicates that cells positive for RA signal comprise $11 \%$ of the epithelium ( $n=4$ sections)(Table2). The epithelium of a 
developing SMG contains at least two distinct cell types, those in the basal layer, and those in supra-basal locations interior to the basal epithelium. Cells positive for RA signaling are present in both the basal and supra-basal compartments (Fig. 3 B).

RA signal is also detected in KRT8-negative non-epithelial tissues. RA signal-positive cells are detected in non-neuronal mesenchyme at the tip of the developing SMG (Fig. 3 C, white arrowhead). Numerous RA signal-positive cells are also detected outside the epithelium in the area around the main duct, where the neurons of the parasympathetic ganglion are known to be located (Fig. $3 \mathrm{~A}$, yellow arrows). RARE-lacZ reporter embryo sections were co-stained for TUBB3 and $\beta$-galactosidase to determine if RA signaling occurs within neurons of the SMG parasympathetic ganglion. Co-staining for the two markers reveals that strong RA signaling is present within many or most of the cell bodies of the developing SMG parasympathetic ganglion (Fig. 3 D-F). Taken together these data indicate that E13.5 SMG have active RA signaling in epithelial cells, in the non-neuronal mesenchyme, and within the neurons the SMG parasympathetic ganglion.

We examined also the presence and distribution of RA signaling relative to KRT8 at later developmental stages. We observe KRT8 is preferentially localized to luminal epithelium of ducts in E14.5 SMG (Fig. 3 G, H), a distribution consistent with previous analyses of KRT8 localization in SMG ducts (Rebustini et al., 2007), and its upregulation in cells that translocate to lumens in prostate (Hudson et al., 2001). Co-staining sections from RARE-lacZ embryos 
for $\square \beta$-galactosidase and KRT8 reveals that RA signaling is dramatically reduced at E14.5 relative to E13.5 (Fig. $3 \mathrm{G}, \mathrm{H}$ ). Counting the number of cells positive for RA signaling relative to the number of epithelial DAPI-positive nuclei indicates that RA signal positive cells comprise less than $1 \%$ of epithelial cells at E14.5 ( $\mathrm{N}=4$ sections) (Table2). At this stage, the RA signaling-positive cells within the epithelium are limited to a few epithelial endbuds, particularly those with the lowest levels of KRT8 (Fig. $3 \mathrm{H}$, blue arrowhead). Endbuds and ducts with relatively high KRT8 have few or no cells positive for RA signaling (Fig. $3 \mathrm{H}$, white asterisks). RA signaling is also detected in a few scattered non-epithelial cells at this stage. At E15.5 RA signaling was not detected by $\beta$-galactosidase staining (data not shown). 

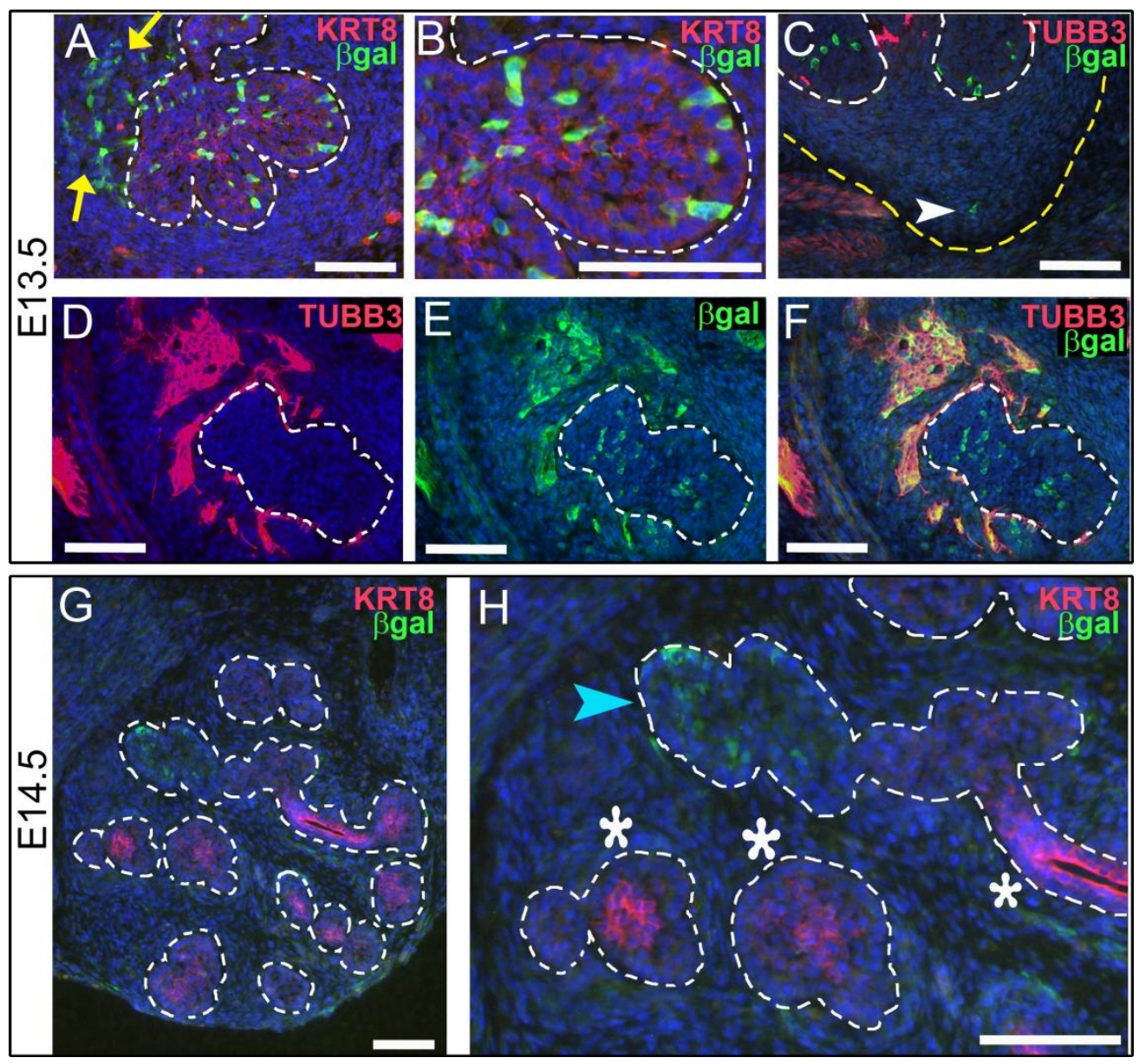

Figure 3. RA signaling occurs in multiple tissues of developing SMG.

Immunostaining for $\beta$-galactosidase on cryosections from embryos carrying the RARE-LacZ reporter transgene reveals the location of RA signaling in developing SMG at E13.5 (A-F) and E14.5 (G-H). (A, B) At E13.5 co-staining for KRT8 and $\beta$-galactosidase reveals numerous cells of the epithelium are positive for RA signaling (cells within dotted outline). Cells positive for RA signaling are also detected in non-epithelial cells, particularly in the area around the main duct (yellow arrows). Examination of an individual endbud (B, (detail of $A)$ ) reveals that RA positive cells are present in basal epithelium and also within interior epithelium that will later form lumens. Co-staining for neurons (TUBB3) and RA 
signaling ( $\beta$-galactosidase) on a posterior section through the apex of the strawberry-shaped SMG $(C)$ reveals RA signaling occurs in a small number of cells in non-neuronal mesenchyme in this region (white arrowhead). (D-F) Costaining for neurons (TUBB3) and RA signaling ( $\beta$-galactosidase) in sections containing the parasympathetic ganglion reveals that many neurons of the SMG parasympathetic ganglion are positive for RA signaling at E13.5. (G,H) By E14.5, the number of SMG cells positive for RA signaling is reduced relative to E13.5. (G) At E14.5 RA positive cells are present in only a few endbuds. (H) KRT8 is expressed strongly in some endbuds (white asterisks) and weakly in others (blue arrowhead). Endbuds with RA positive cells correspond to those with a low level of KRT8 (blue arrowhead), while endbuds and ducts with a higher level of KRT8 have little or no detectable RA signaling (white asterisks). White dotted lines, edge of epithelium; yellow arrows, non-epithelial RA positive cells in vicinity of main duct; yellow dotted line, edge of SMG mesenchyme; white arrowhead, RA signal positive cell in non-neuronal mesenchyme at tip of strawberry-shaped SMG; blue arrowhead, endbud positive for RA signaling with low KRT8; white asterisks, endbuds and ducts with no detectable RA signal with high KRT8. Scale bars $=100 \mu \mathrm{m}$. 
Table 2. Number of RA positive cells in E13.5 and E14.5 SMG

\begin{tabular}{|l|l|l|l|l|}
\hline E13.5 & & RARE & & \\
SMG & \#cells & positive & $\%$ & Average\% \\
\hline 1 & 589 & 92 & 15.62 & 10.59 \\
\hline 2 & 413 & 37 & 8.96 & \\
\hline 3 & 478 & 40 & 8.37 & \\
\hline 4 & 265 & 25 & 9.43 & \\
\hline E14.5 & & & & \\
\hline SMG & \#cells & positive & $\%$ & Average\% \\
\hline 1 & 889 & 3 & 0.33 & 0.69 \\
\hline 2 & 924 & 10 & 1.08 & \\
\hline 3 & 917 & 6 & 0.654 & \\
\hline
\end{tabular}




\section{RA activity ex vivo the whole SMG}

It is well-established that mouse SMG can be cultured in vivo. Because we observed RA signaling in glands in vivo, we wondered if RA signaling occurs in SMG developing ex vivo on culture medium deprived of RA or any precursors that can possibly be converted into RA. We were, therefore, interested to know how RA signaling is distributed in whole glands cultured ex vivo for different periods of time. We hypothesized that tissues placed in culture retained retinoids from in vivo embryo. Therefore, we cultured whole SMG glands from embryos carrying the RARE-lacZ reporter transgene for different periods of time and stained the cultured specimens to visualize RA signaling.

When E13.5 SMG are freshly isolated, they exhibit strong RA signaling that is mainly focused in the epithelium (Figure4A, A'). After 48 hours in culture, RA positive cells were present, but the signal is scattered among individual cells throughout the gland, coinciding mainly with the epithelium of developing gland (Figure4B,B'). After 72 hours of ex vivo culture, RA activity is still robust, but pattern appeared to change. SMG that were cultured for 3 days, show active RA signal that appears to coincide with the position of non-epithelial tissues surrounding the main duct which is most probably represented by parasympathetic nerve ganglion. (Figure4C,C')

One important feature of LacZ staining analysis is the protein produced in a response of activation of a lacZ gene can be stable for a long period of time estimated at 24-48 h (Gonda et al., 1989 and McCutcheon et al., 2010). Thus, 
staining identified over a 2 or 3 day time period, which is the duration of conventional SMG culture experiment, may represent the $\beta$-galactosidase activity of lingering protein produced significantly earlier within the animal prior to culture, and not from active RA signaling. In order to discriminate if the RARE-lacZ $\beta$ galactosidase detected in cultured SMG indicates active RA signaling, we assessed RARE-lacZ expression from SMG that remained in cultured for 5 days. We choose this time period because it is considerably longer than the half-life of the protein. We observed strong RA signaling in SMG cultured for 5 days ex vivo. The expression of RA activity at this stage closely resembles the 3-day stage with RA signal coinciding with non-epithelial tissues near the main duct (Figure $4 \mathrm{D}$ and $\mathrm{D}$ '). These results show that retinoids present within the freshly dissected tissue can persist in cultured SMG for a prolonged period of time and contribute to active RA signaling despite the absence of Vitamin A or RA in the culture medium. 


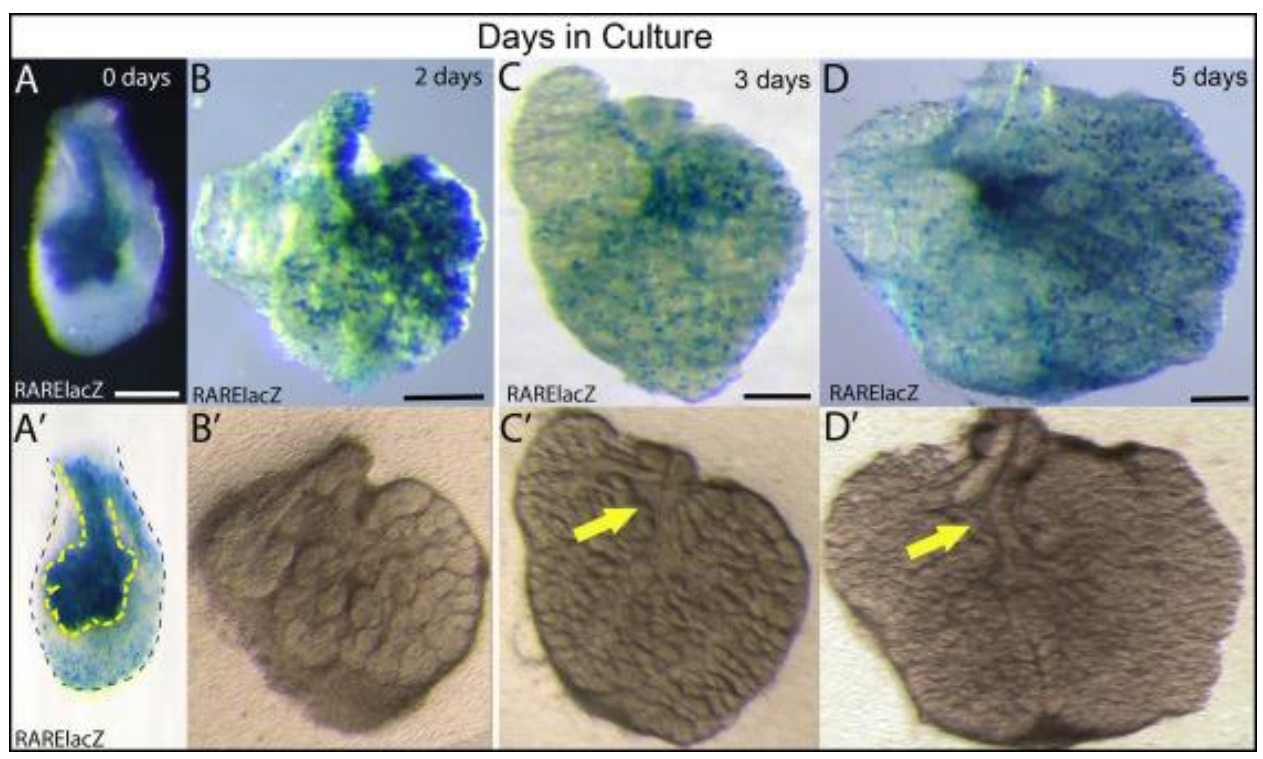

Figure 4: RA signal in whole SMG cultured for different time periods.

(A) Freshly isolated E13.5 SMG signal is concentrated in the epithelium. (A')

Epithelium and mesenchyme outlined. (B) SMG cultured for 2 days strong RA signaling mostly focused in the epithelium of submandibular gland. (B') Bright field picture showing epithelium outline. (C) SMG cultured for 3 days RA signal remains but it is redistributed. RA signal is centered in the area that coincides with the location of nerve ganglion. (C') Bright field picture showing epithelium outline yellow arrow on the main duct. (D) SMG cultured for 5 days RA signaling persists after 5 days strongest signal is located in a periductal area where nerve ganglion is situated. (D') Bright field picture showing epithelium outline and yellow arrow on main SMG duct and near ductal tissue. 
In order to visualize the overall distribution of RA signaling within the highly 3-dimensional structure of a developing SMG epithelium, we evaluated RA signaling in whole mount ER specimens. Isolated ER from E13.5 SMG of RARElacZ reporter embryos were immunostained as whole mount specimens for Ecadherin, which marks all epithelium, and for $\beta$-galactosidase, which marks the cells with active RA signaling. Confocal micrographs were collected through the entire specimen and Z-stacks of image planes were collapsed into a single image. The resulting whole mount images reveal RA signaling is active in a mosaic distribution of cells, and is present within the endbuds and main duct of the E13.5 SMG epithelium (Fig. 5 A). RA signal positive cells were not detected preferentially at any position or site.

Because much analysis of salivary gland biology has been elucidated through the means of ex vivo cultured $\mathrm{ER}$, we sought to determine if RA signaling occurred in that context. We, therefore, assessed RA signaling in isolated ER cultured from E13.5 RARE-lacZ reporter embryos. After two days in culture, ER display a mosaic pattern of active RA signaling (Fig. 5 B), which was similar to the distribution of the signal in freshly isolated ER (Fig. 5A). In both cases, RA signal positive cells are present in ducts and endbuds. 


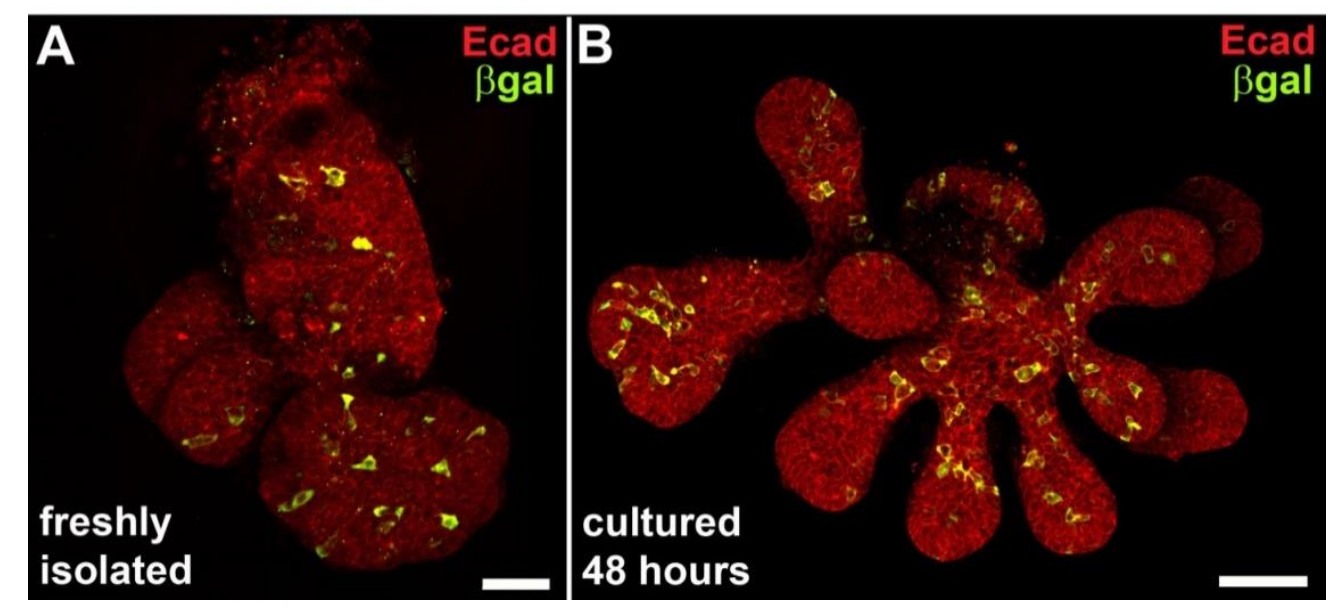

Figure. 5. Mosaic RA signaling in ducts and endbuds persists during

culture. Confocal micrographs of whole mount epithelial tissue isolated from E13.5 SMG of RARE-lacZ reporter embryos immunostained for RA activity and epithelium reveals the distribution of RA signaling in main duct and endbuds, and persistence of signaling in culture. (A) Staining freshly isolated ER for epithelium (E-cadherin) and RA signaling ( $\beta$-galactosidase) reveals a mosaic pattern of RA signaling in main duct and endbuds. (B) RA signaling is detected in ER after 48 hours in culture in matrigel. The mosaic distribution of RA positive cells in ducts and endbuds is similar to that observed in freshly isolated ER. Scale bars $=50 \mu \mathrm{m}$ with respect to a single image plane. 


\subsection{Standard curve Verification of qPCR primers in cultured ER}

In order to assess changes in expression of certain genes, we have decided to measure mRNA levels using qPCR. Primers were tested in order to verify their efficiency using standard dilution curve method. All primers were tested by using serial dilution at 5 concentrations, each concentration made in duplicate. Primers that were selected for the QPCR had efficiency in the range from $93 \%$ to $112 \%$ (Fig. 6 - Fig. 12). 
Gene: Gapdh

Forward primer: ACAGTCCATGCCATCACTGCC

Reverse primer: GCCTGCTTCACCACCTTCTTG

EFFICIENCY: $106.425 \%$

2016.05.26

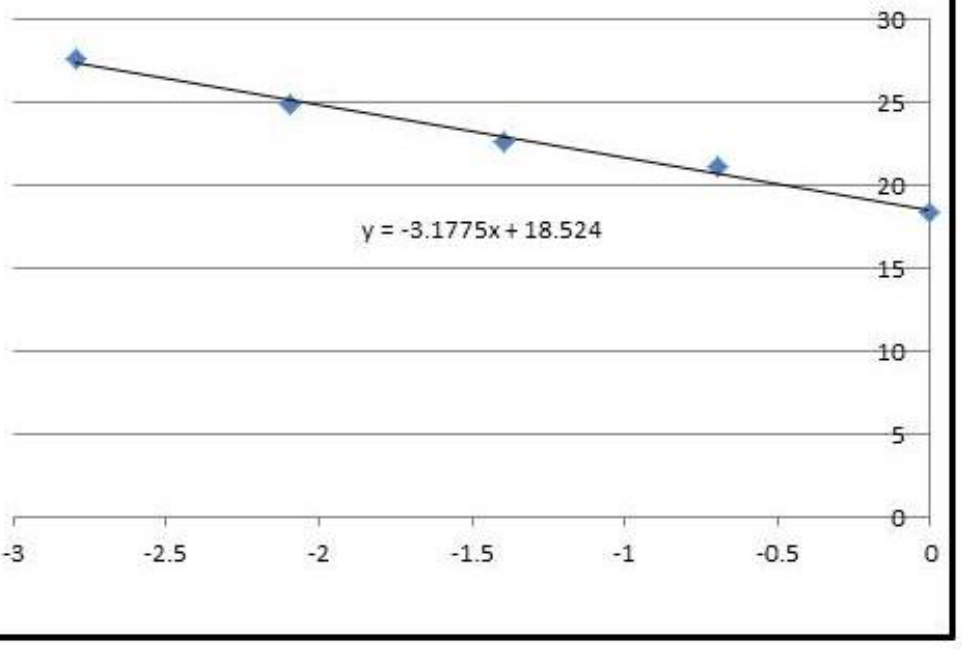

Gene: $\underline{K r t 5}$

Forward primer: TCCAGTGTGTCCTTCCGAAGT

Reverse primer: TGCCTCCGCCAGAACTGTA

EFFICIENCY: $107.808 \%$

2016.05.26

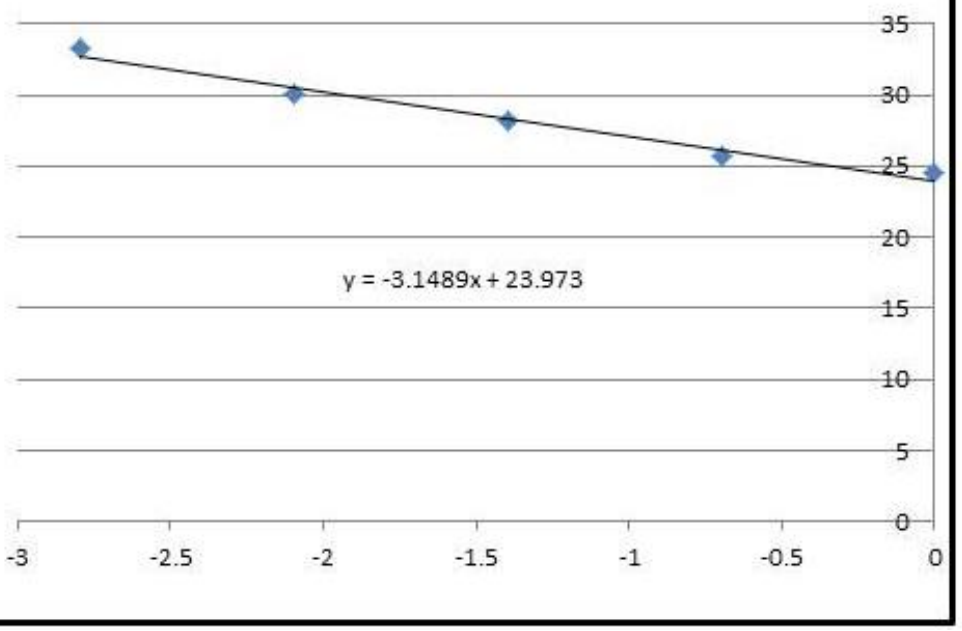

Figure 6: Gapdh and Krt5 primer efficiency standard curve and date of verification 
Gene: $\underline{\text { Krt19 }}$

Forward primer: GGGGGTTCAGTACGCATTGG

Reverse primer: GAGGACGAGGTCACGAAGC

EFFICIENCY: $110.478 \%$

2016.05.26

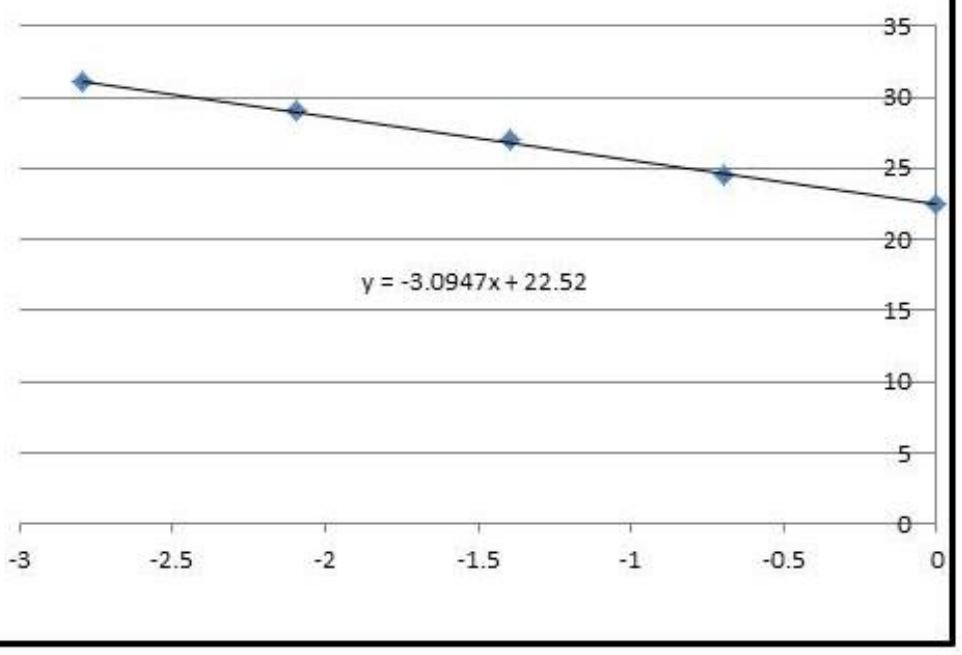

Gene: $\underline{\text { Sox } 2}$

Forward primer: GCGGAGTGGAAACTTTTGTCC

Reverse primer: CGGGAAGCGTGTACTTATCCTT

EFFICIENCY: $112.069 \%$

2016.05.29

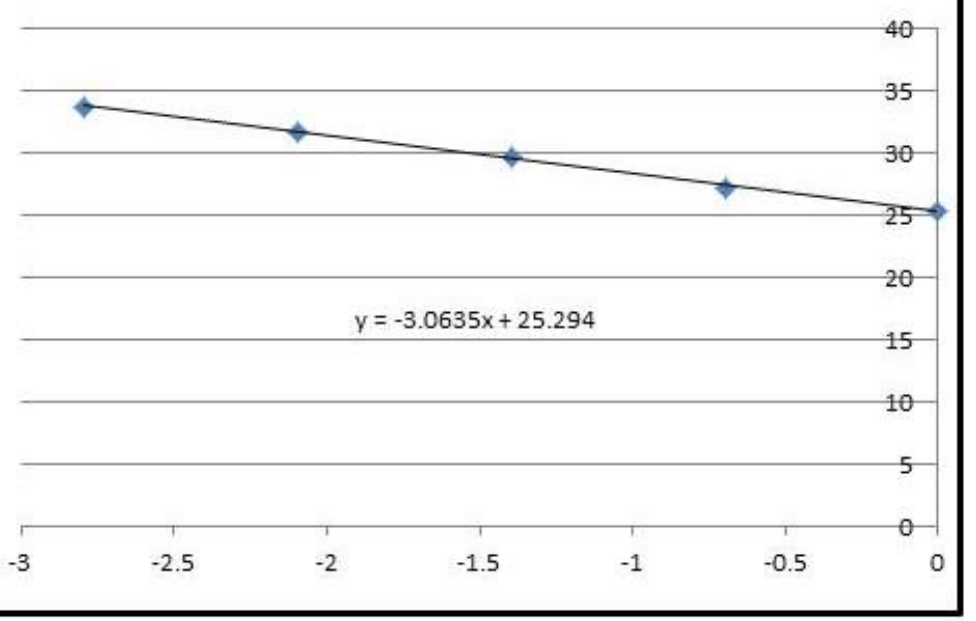

Figure 7: Krt19 and Sox2 primer efficiency standard curve and date of verification 
Gene: $\underline{K l f 4}$

Forward primer: GTGCCCCGACTAACCGTTG

Reverse primer: GTCGTTGAACTCCTCGGTCT

EFFICIENCY: $108.586 \%$

2016.05.26

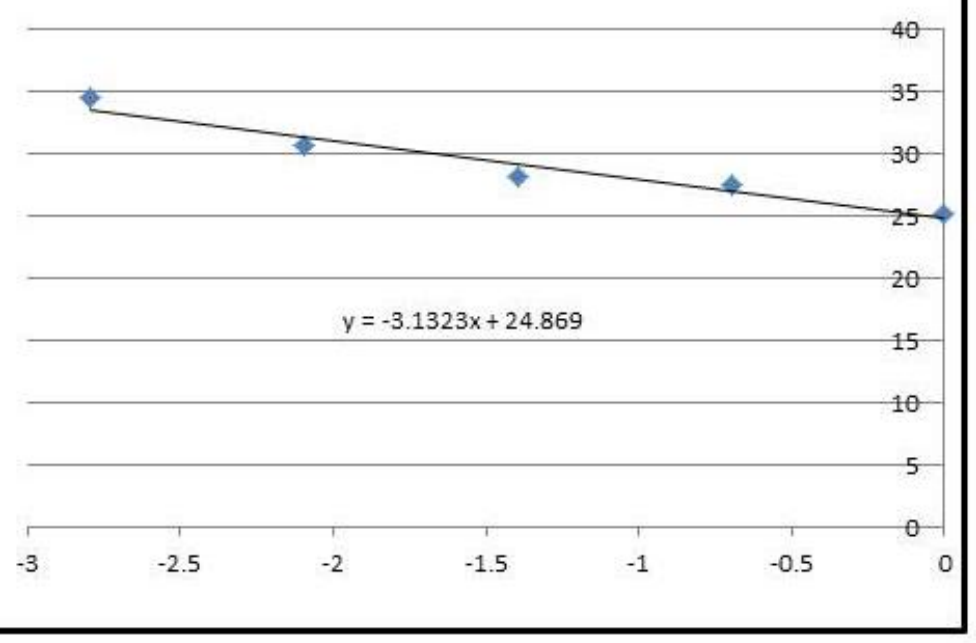

Gene: $\underline{K r t 8}$

Forward primer: TCCATCAGGGTGACTCAGAAA

Reverse primer: CCAGCTTCAAGGGGCTCAA

EFFICIENCY: $109.176 \%$

2016.05.29

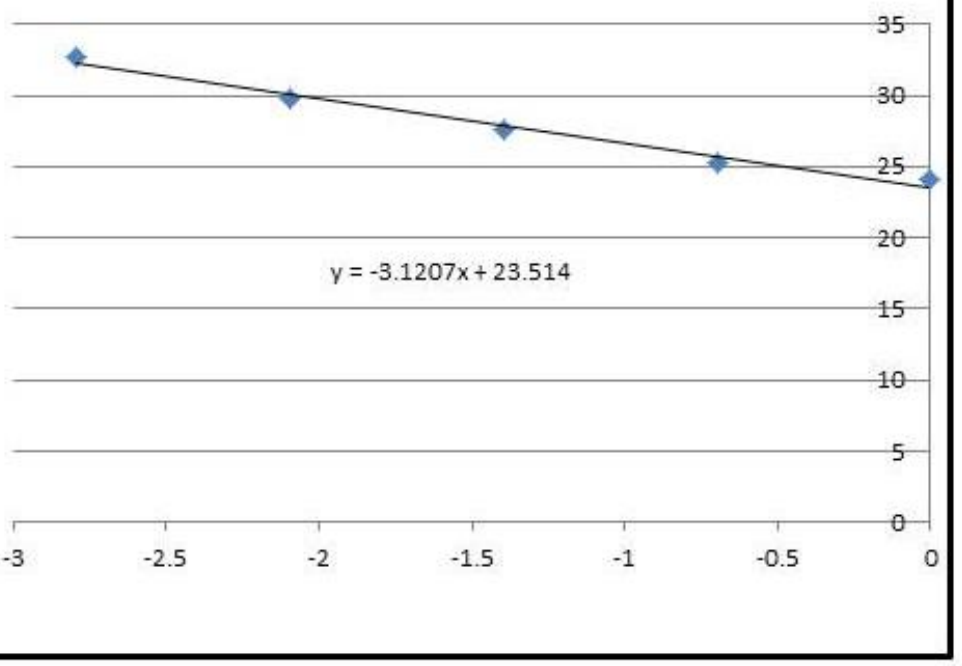

Figure 8: KIf4 and Krt8 primer efficiency standard curve and date of verification 
Gene: Myc

Forward primer: ATGCCCCTCAACGTGAACTTC

Reverse primer: CGCAACATAGGATGGAGAGCA

EFFICIENCY: $101.823 \%$

2016.05.29

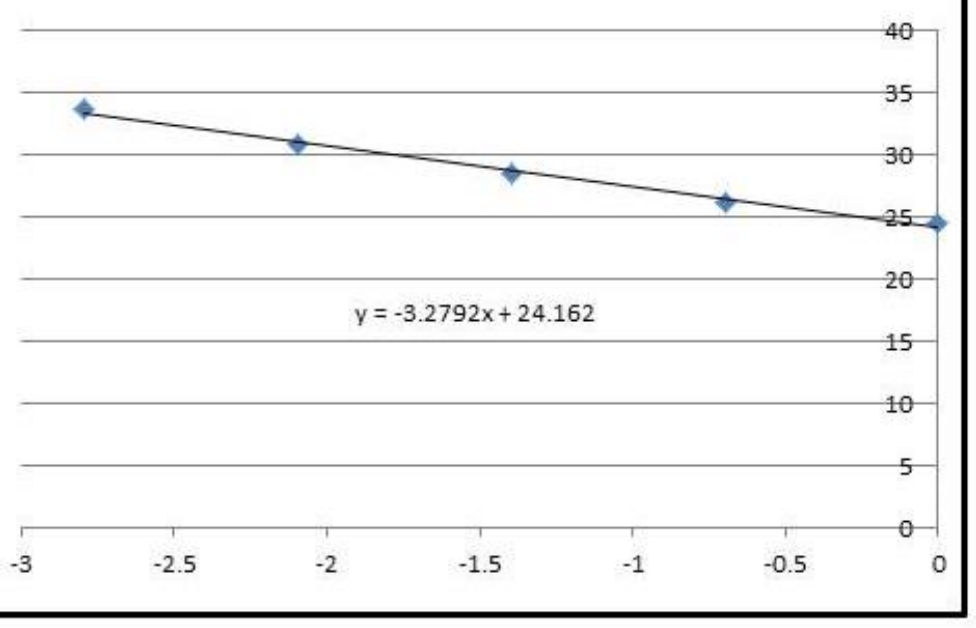

Gene: $\underline{A c t b}$

Forward primer: GGCTGTATTCCCCTCCATCG

Reverse primer: CCAGTTGGTAACAATGCCATGT

EFFICIENCY: $106.898 \%$

2016.08.25

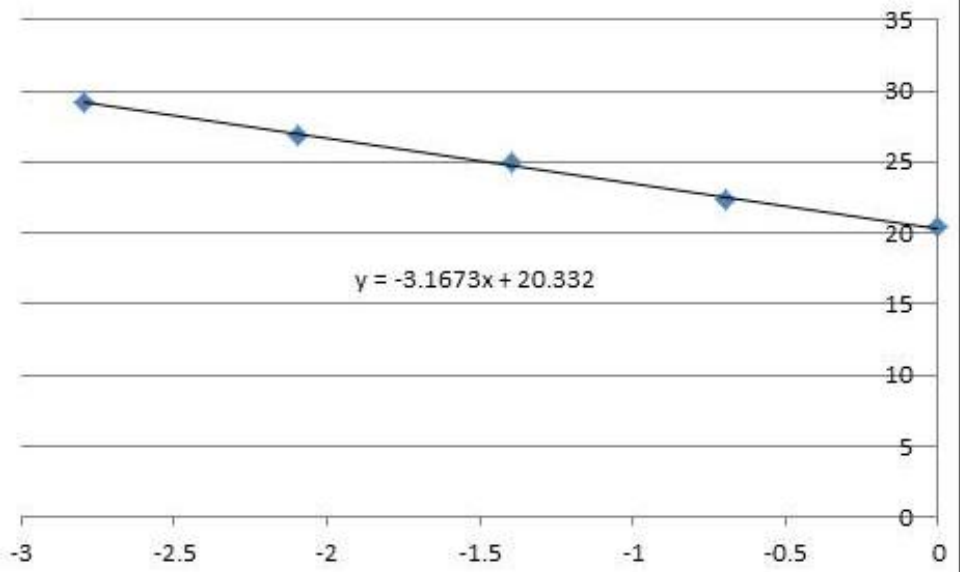

Figure 9: $M y c$ and Actb primer efficiency standard curve and date of verification 
Gene: Etv5

Forward primer: TCAGTCTGATAACTTGGTGCTTC

Reverse primer: GGCTTCCTATCGTAGGCACAA

EFFICIENCY: $107.184 \%$

2016.08.25

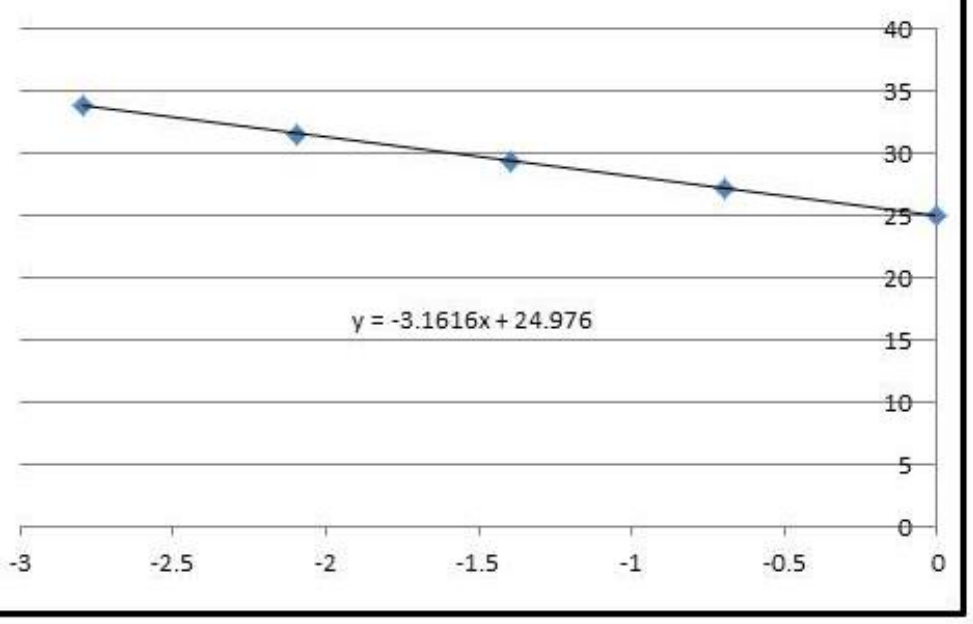

Gene: Krt14

Forward primer: AGCGGCAAGAGTGAGATTTCT

Reverse primer: CCTCCAGGTTATTCTCCAGGG

EFFICIENCY: $98.557 \%$

2016.08.25

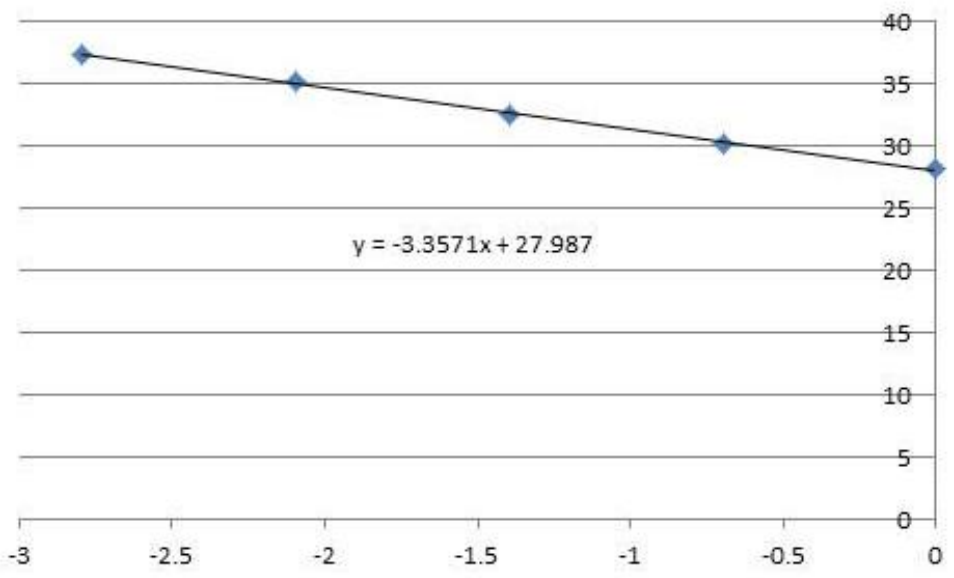

Figure 10: Etv5 and Krt14 primer efficiency standard curve and date of verification 
Gene: $\underline{\text { Kit }}$

Forward primer: TCATCGAGTGTGATGGGAAA

Reverse primer: GGTGACTTGTTTCAGGCACA

EFFICIENCY: 93.727\%

2016.09.07

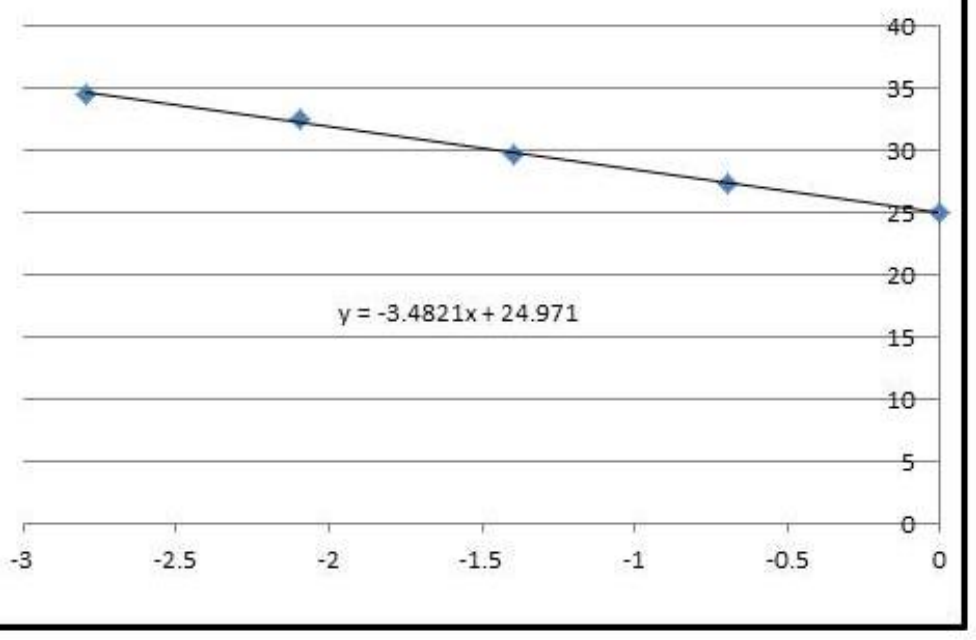

Gene: Top2a

Forward primer: CAACTGGAACATATACTGCTCCG

Reverse primer: GGGTCCCTTTGTTTGTTATCAGC

EFFICIENCY: $108.147 \%$

2016.11.03

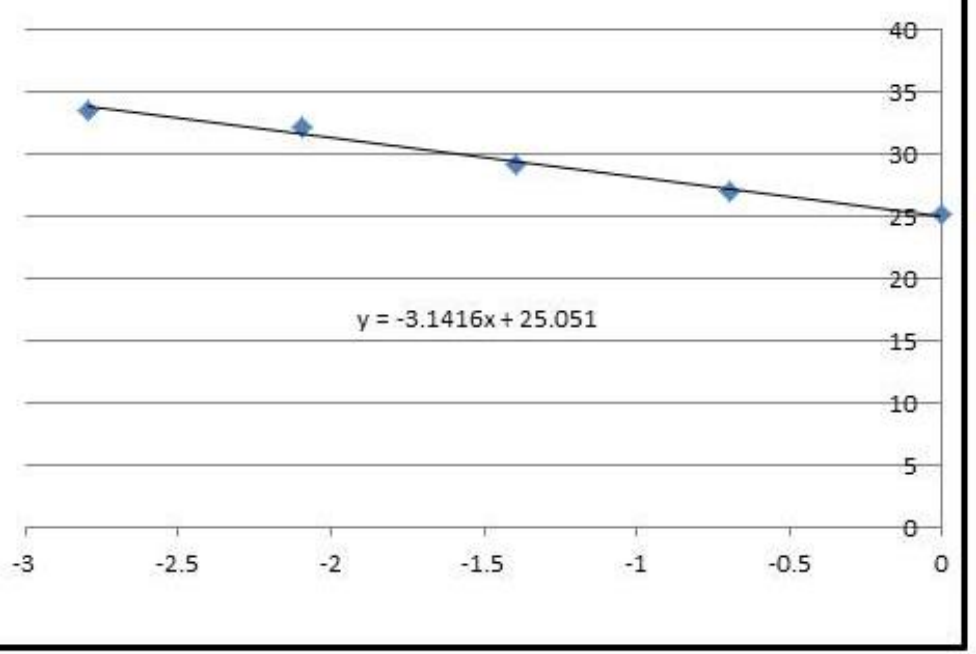

Figure 11: Kit and Top2a primer efficiency standard curve and date of verification 
Gene:Mki67

Forward primer: ATCATTGACCGCTCCTTTAGGT

Reverse primer: GCTCGCCTTGATGGTTCCT

EFFICIENCY: $106.945 \%$

2016.11.03
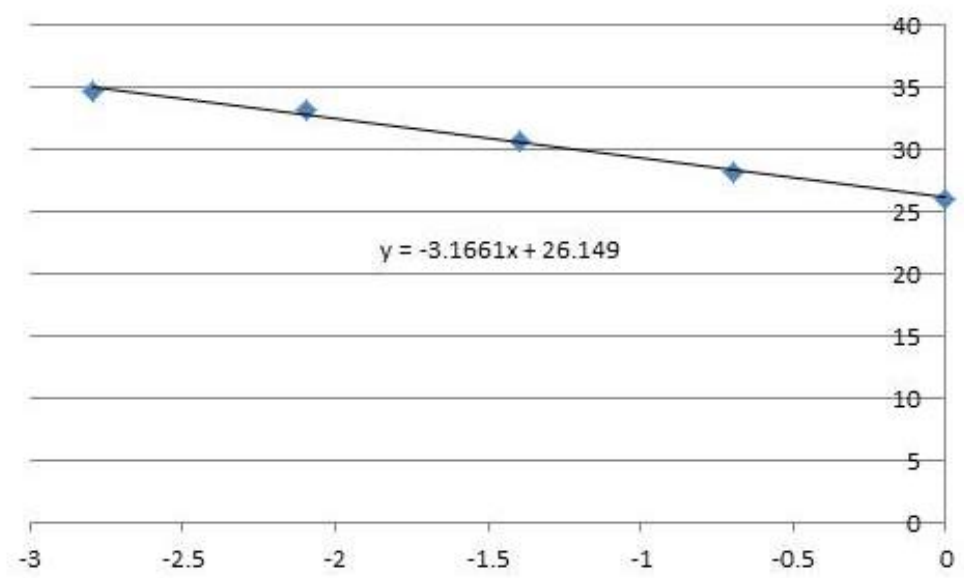

Figure 12: Mki67 primer efficiency standard curve and date of verification 


\subsection{Inhibition of RA signaling impairs branching morphogenesis and FGF10 activity in cultured ER}

In order to determine if RA signaling influences SMG development by direct action within the epithelial tissue, we examined whether RA signaling is important for the growth of isolated ER cultured ex vivo. We cultured isolated ER in the presence or absence of a chemical inhibitor of RA signaling, BMS 493, which is a pan-RAR inverse agonist. ER were isolated from E13.5 SMG by treatment with dispase I and microdissection. ER were cultured for 48 hours on filters supported over medium containing $5 \mu \mathrm{M}$ BMS 493 or on control medium containing an equivalent volume of the solvent DMSO.

Prior to culture, each isolated ER was a small compact structure with 3-6 small endbuds (Fig.13 A). After 48 hours, ER that had been cultured on control medium grew robustly with extensive branches, large rounded endbuds, and elongated translucent ducts (Fig. 13 B). In contrast, ER that had been cultured on medium containing BMS 493 grew in an atypical manner (Fig, 13 C). BMS 493-treated ER had fewer branches and smaller endbuds, with ducts that were narrow, optically dense, and kinked. Counting the number of endbuds revealed that ER grown on medium containing BMS 493 had significantly fewer endbuds, $\mathrm{N}=7$ ER control, N=8 ER BMS 493, $p \leq 0.03$ (Fig. $13 \mathrm{D}$ ). The amount of tissue growth for control and BMS 493-treated ER was assessed by tracing the outline of each specimen imaged at the end of the culture period and measuring the 2dimensional area. Tissue growth, as measured by area, was not significantly different between control and BMS-treated ER specimens (Fig. 13 E). These 
data reveal that RA signaling is important for branching morphogenesis of ER cultured in the absence of mesenchyme, ex vivo, demonstrating that RA influences epithelial growth by direct action in epithelial tissue.

It is well established that branching morphogenesis requires signaling by the growth factor FGF10 through its receptor FGFR2b (Steinberg et al., 2005), and FGF10 is included as an additive to the ER culture medium. In order to determine if the aberrant branching morphogenesis in BMS 493-treated ER cultures was associated with an altered FGF10 activity, we assessed expression of Etv5, a downstream target of FGF10 signaling in epithelial tissues (Firnberg and Neubuser, 2002; Liu et al., 2003; Michos et al., 2010). Inhibition of RA signaling by treatment with BMS 493 caused a $\geq 5$-fold downregulation of Etv5 relative to controls, $\mathrm{N}=3 \mathrm{ER} /$ condition $\times 2$ experiments, $\mathrm{p}=0.01$, (Fig. $13 \mathrm{~F}$ ). These data demonstrate that FGF10 signaling is blocked when RA signaling is inhibited in cultured ER. Thus, RA signaling positively enhances FGF10 activity in this context. 


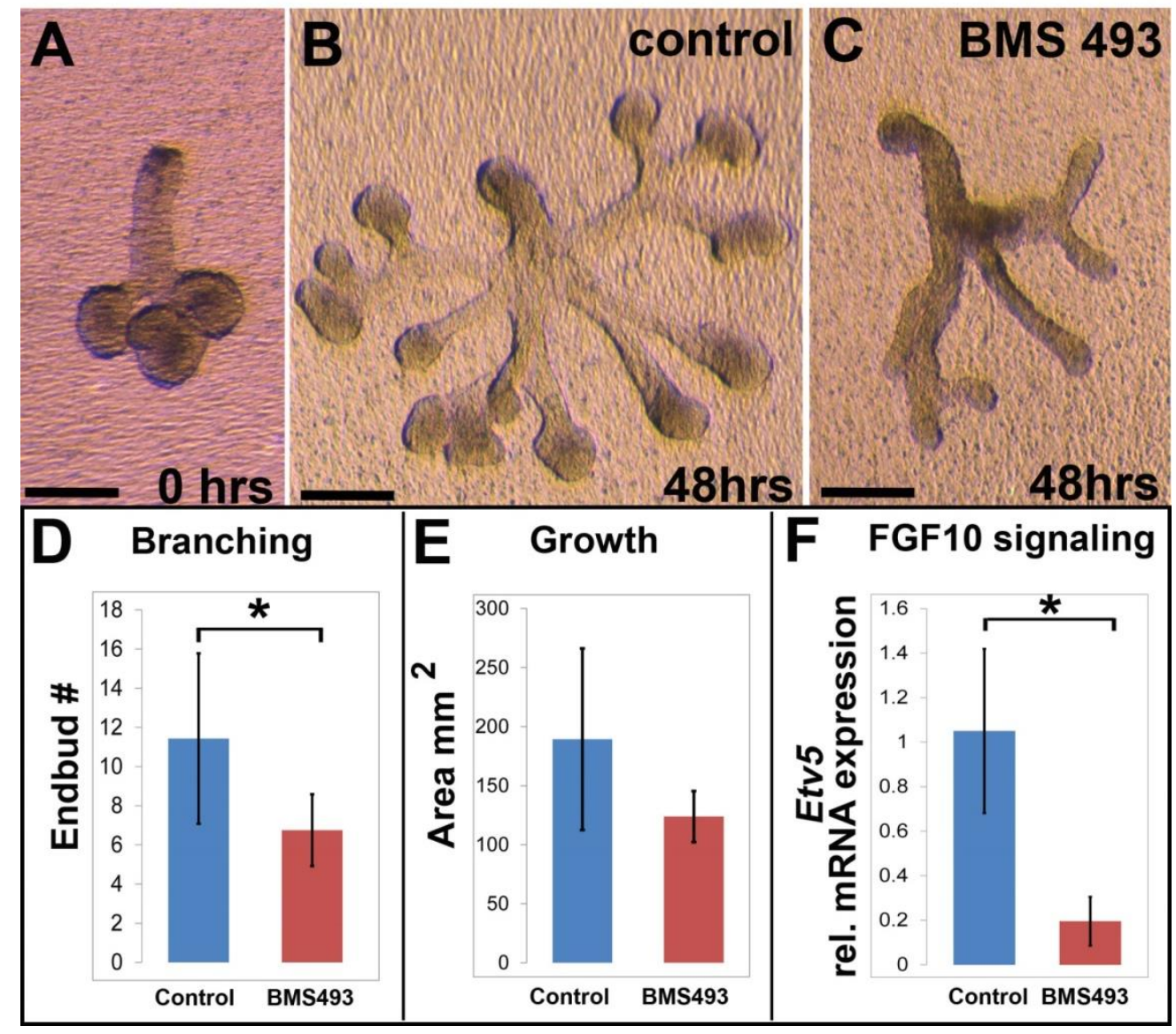

Figure 13. RA signaling regulates the developmental growth of epithelium by direct action in epithelial tissue. Inhibition of RA signaling by BMS 493 impedes ex vivo growth of isolated ER. (A) Freshly isolated E13.5 ER with 3-6 endbuds were placed in culture. (B) ER cultured for 48 hours on control medium grew well, branched and formed numerous elongated translucent ducts. (C) ER cultured on medium containing BMS 493 had abnormal growth with fewer branches and a dense kinked appearance. (D) ER grown on BMS 493 had significantly fewer endbuds than those grown on control medium, Control ER $\mathrm{N}=$ 7, BMS 493 ER N=8, $p \leq 0.03$. (E) The area of ER grown on BMS 493 medium was not significantly different from controls, as assessed by outlined area. (F) 
Expression of Etv5, a known target of FGF10 regulation, is significantly downregulated in ER cultured on BMS 493 relative to control, $N=3 \mathrm{ER} /$ condition $\times 2$ experiments, $p=0.01$. Scale bars $=200 \mu \mathrm{m}$. 


\subsection{Inhibition of RA signaling leads to downregulation of proliferation activity.}

The proliferation of epithelial cells is an essential developmental process in the formation of a properly functioning salivary gland. In order to determine if blocking of RA signaling impacts epithelial proliferation, we measured the mRNA expression of two proliferation markers. Mki67 is the gene encoding the antigen Ki67 that is widely used to identify proliferating cells. The Mki67 gene is expressed preferentially in the G2 phase of the cell cycle (Ishida et al., 2001; Whitfield et al., 2002). Top2a encodes topoisomerase 2, which is expressed in the S-phase of the cell cycle (Goswami et al., 1996). To determine if proliferation is altered by inhibiting RA signaling we analyzed expression of Mki67 and Top2a by qPCR. Three independent experiments were conducted and RNA was collected from Control and BMS 493-treated groups. The result was consistent with a change in FGF10 signaling. Both Mki67 and Top2a were significantly downregulated in BMS 493-treated groups compared with control groups $\mathrm{N}=3$ independent culture experiments with 6-8 ER/condition $\times 3$ technical qPCR replicates (Figure14), Mki67p $=0.0343 ;$ Top2a $p=0.026$. Considering the significant downregulation of both proliferation markers in BMS 493-treated specimens, we can conclude that RA signaling in developing SMG epithelium is crucial for cell proliferation. 


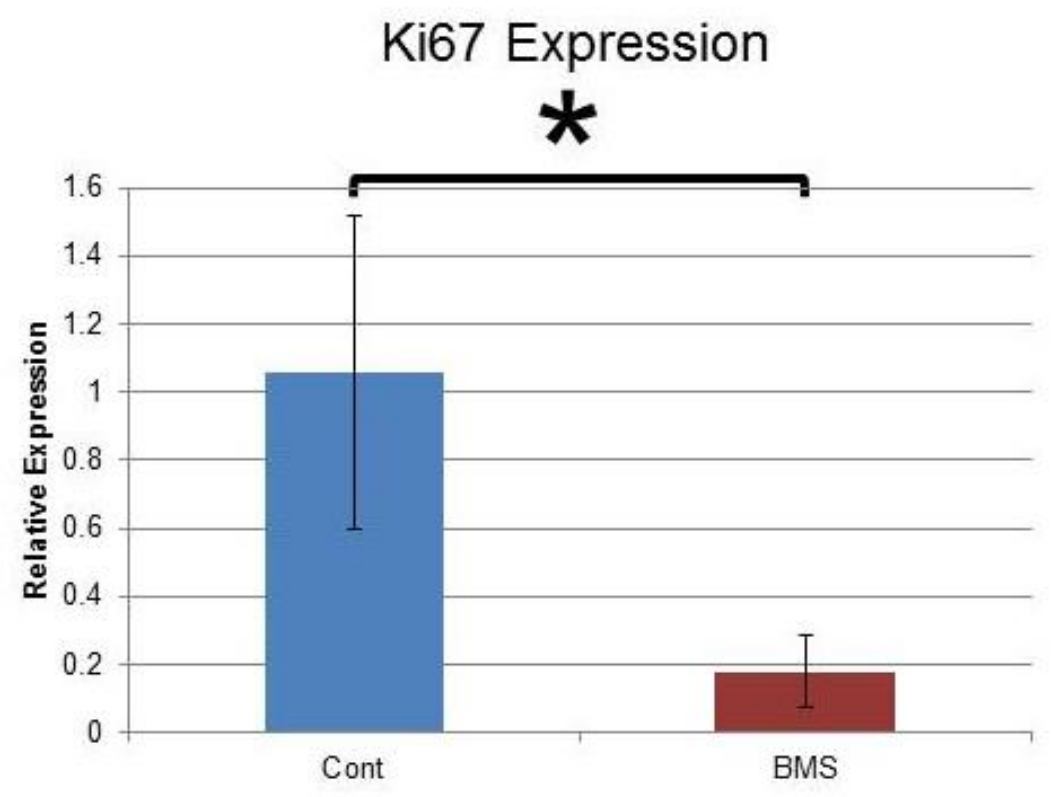

\section{Top2a Expression}

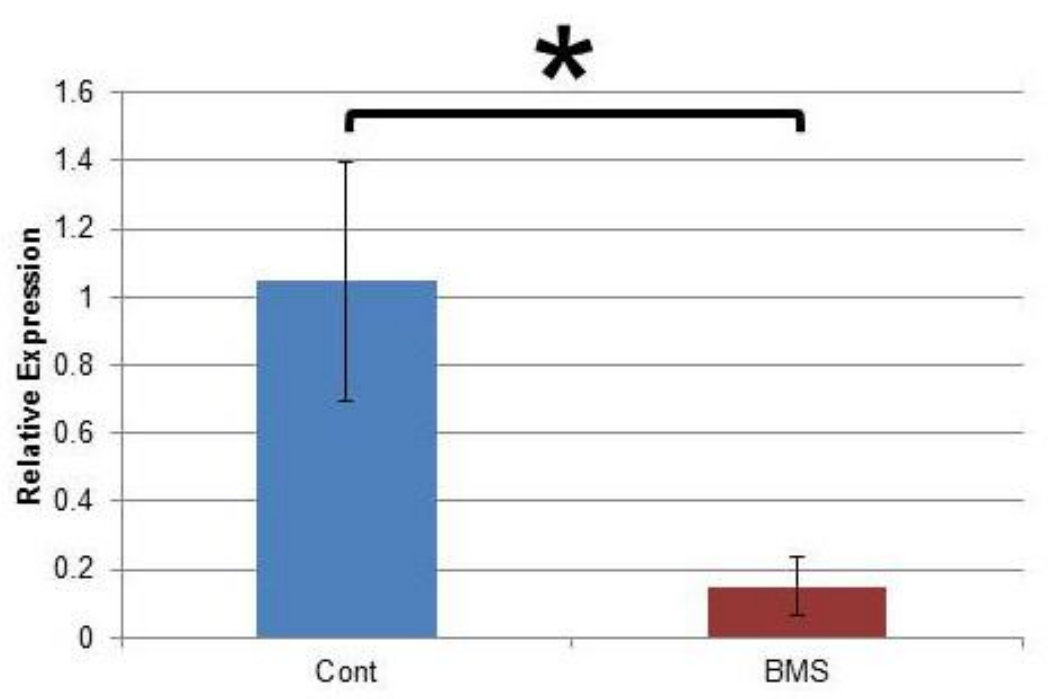

Figure14: Expression of proliferation markers Mki67 and Top2a.

Both proliferation markers demonstrated significant downregulation in specimens treated with BMS 493. 


\subsection{Block of RA signaling upregulates expression of KRT5}

An important marker of basal epithelial progenitor cells in SMG ducts is KRT5. Krt5 gene expression has been shown to be negatively regulated by RA in epithelial cells of the epidermis (Ohtsuki et al., 1992; Radoja et al., 1997; Tomic-Canic et al., 1996). We, therefore, sought to determine if RA signaling regulates KRT5 in developing salivary epithelium. To that end, we cultured ER in the presence or absence of RAR inhibitor BMS 493 and assessed the level and distribution of KRT5 protein by confocal microscopy. ER from E13.5 RARE-lacZ reporter embryos were isolated and cultured for 48 hours on medium containing BMS 493 or on control medium. Following culture, ER were fixed as whole mount specimen and immunostained for KRT8 to visualize epithelium, for $\beta$-galactosidase to visualize RA signaling activity, and for KRT5. Immunostained specimens were imaged by confocal microscopy.

Consistent with our initial ER culture experiments (Fig. 13 A-E), ER from RARE-lacZ embryos cultured on BMS 493 exhibited abnormal growth and branching relative to specimens grown on control medium. BMS 493-treated ER had fewer endbuds, shorter branches and a kinked morphology (Fig. 15 A B). Immunostaining for $\beta$-galactosidase to detect $\mathrm{RA}$ signaling revealed a reduction in the amount of RA signaling in ER cultured on BMS 493 (Fig. 15 C, D). To quantify the reduction of RA signaling in cultured ER the sum of $\beta$-galactosidase immunofluorescent signal was measured using IMARIS image analysis software. BMS 493 treated ER had $\geq 2$-fold reduction in the amount of $\beta$-galactosidase fluorescence relative to controls ( $N=3 E R /$ condition $\times 2$ experiments, $p \leq 0.02)$. 
With respect the KRT5, ER cultured on control medium had only a small amount of KRT5 at the outflow end of the main duct (the main duct being identifiable owing to a larger diameter and lack of branches) (Fig. $15 \mathrm{E}, \mathrm{G})$. No KRT5 was observed within secondary ducts or endbuds in any control specimens. In contrast, ER cultured on medium containing BMS 493 exhibited dramatically upregulated levels of KRT5 in all ducts and endbuds (Fig. 15 F, H). Measuring the amount of fluorescence signal by confocal microscopy demonstrated that the amount of KRT5 protein per specimen was increased $\geq 4$-fold in BMS 493treated ER than control ER, ( $N=3 \mathrm{ER} /$ condition $\times 2$ experiments, $\mathrm{p} \leq 0.002)$. Ectopic high-level KRT5 expression was restricted to cells of the basal epithelial layer (Fig. $15 \mathrm{~K}$ ). These data demonstrate that inhibition of RA signaling elevates KRT5 protein ectopically in a basal epithelial layer of all ducts and endbuds of cultured ER. The elevated levels of KRT5 in BMS 493 treated specimens indicate that KRT5 is negatively regulated by RA in specimens cultured on control medium. 


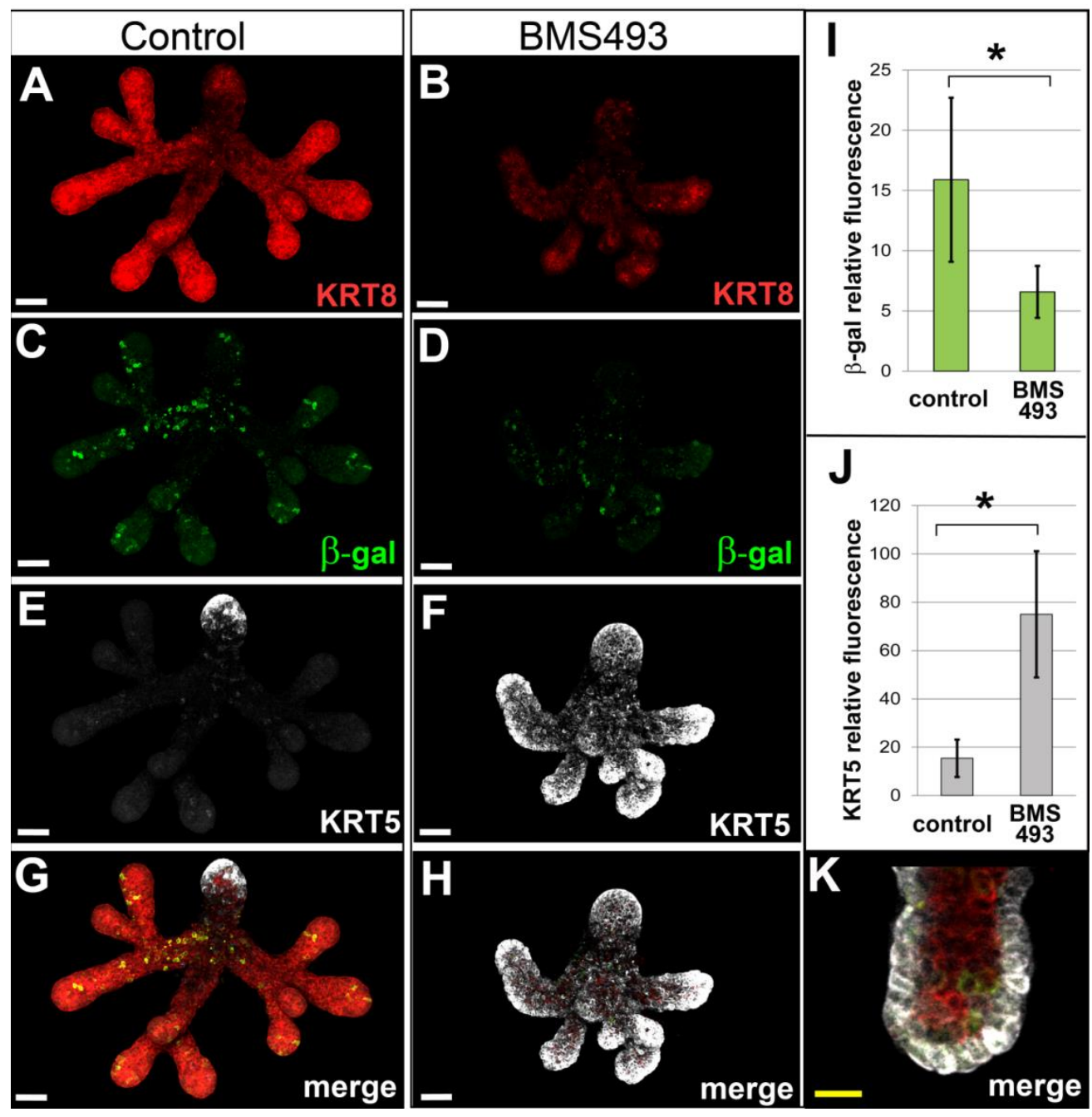

Figure 15. Inhibition of RA signaling in cultured ER upregulates ductal progenitor marker KRT5. Immunostain analysis reveals dramatically elevated the level of KRT5 in ER specimens cultured on medium containing BMS 493 relative to specimens grown on control medium. ER cultured for 48 hours on medium containing BMS 493 (B) were smaller with fewer branches and endbuds relative to their counterparts grown on control medium $(A)$ as visualized by staining for KRT8. RA signaling, visualized by $\beta$-galactosidase fluorescence signal was reduced in ER cultured on BMS 493 (D) relative to control specimens (C). The amount of RA signaling, as measured by the sum of relative 
fluorescence intensity signal for $\beta$-galactosidase, is reduced $\geq 2$-fold, $p=0.02, N$ $=6 \mathrm{ER}(\mathrm{I}) . \mathrm{KRT} 5$ is dramatically upregulated of ER cultured on BMS $493(\mathrm{E})$ relative to controls (D). For ER grown on control medium KRT5 signal is limited to a few cells at the tip of the main duct $(E, G)$. In contrast, ER grown on medium containing BMS 493 had highly elevated KRT5 signal in all endbuds and ducts $(F, H)$. Elevated KRT5 expression in BMS 493-treated ER was restricted to cells of the basal epithelium (K). The amount of KRT5 protein, as measured by the sum of relative fluorescence intensity signal, was elevated $~ 5$-fold in BMS 493treated ER relative to control specimens, $N=6 \mathrm{ER}, \mathrm{p}=0.002(\mathrm{~J})$. White scale bars $50 \mu \mathrm{m}$, yellow scale bar $=20 \mu \mathrm{m}$. 


\subsection{Addition of RA signaling impairs branching morphogenesis in cultured}

ER

Because blocking RA signaling with BMS 493 impacted growth of ER in culture, we hypothesized that addition of RA to culture medium would alter the phenotype of cultured ER. In order to establish culture conditions, we tested the effect of RA treatment on ER growth and branching over a range of RA concentrations from $300 \mathrm{nM}, 400 \mathrm{nM}, 500 \mathrm{nM}$. In this initial analysis, we observed that treatment of ER with 500nM may have altered the branching morphogenesis (Figure16). RA treated specimens appeared to have more branches compared to control group.

We then performed three independent culture experiments in order to quantify the difference in branching between ER control grown on control medium or ER grown on medium containing 500nm RA (Figure17). The number of branches was counted and student T-test was used to assess the statistical significance of the difference. (Table3). No significant difference was identified between the control and RA treated samples. In order to determine whether RA signaling was increased in the specimens cultured on RA, immunostaining was performed on specimens carrying the RARE-lacZ transgenic reporter. Immunostaining showed no significant upregulation of RA signaling (Figure18).

Owing to the lack of increase in RA signaling, we speculate that these experiments are compromised by technical problems owing to the nature of RA. The molecule is very labile and breaks down easily when exposed to light or oxygen. Moreover, the lack of phenotypic change in the RA treated samples could result from a difference in growth characteristics depending on subtle 
differences in initial stage of specimens. Our observation may suggest that specimens closer to E13.0 stage of development grow slower and have less number of branches compared to specimens that are closer to E14.0 when they are put in the culture. Therefore, more experiments are required in conditions that assure RA stability, and rigorously control for developmental stage of specimens plated in order to make final conclusions about the effect of RA treatment on cultured ER. 
FGF10(500ng/ml)+ DMSO+ $\mathrm{H} / \mathrm{S}(500 \mathrm{ng} / \mathrm{ml})$

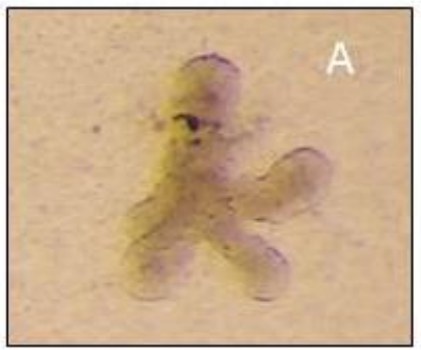

$\mathrm{FGF} 10+\mathrm{H} / \mathrm{S}+$ $\mathrm{RA}(300 \mathrm{nM})$

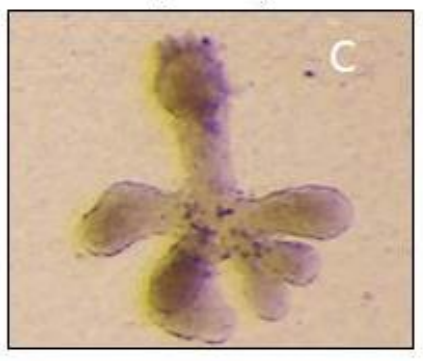

$\mathrm{FGF} 10+\mathrm{H} / \mathrm{S}+$

$\mathrm{RA}(100 \mathrm{nM})$

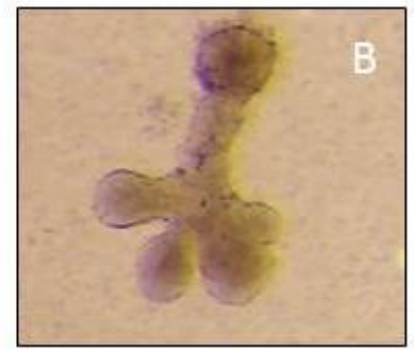

$\mathrm{FGF} 10+\mathrm{H} / \mathrm{S}+$ $\mathrm{RA}(500 \mathrm{nM})$

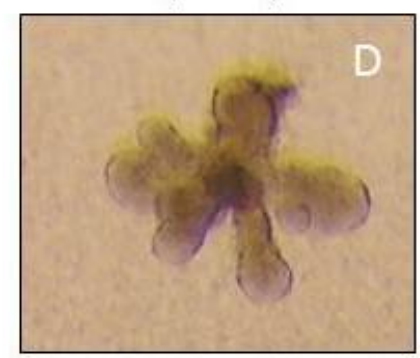

Figure16: Test of different concentrations of RA on ER cultured for 1 day.

(A) Control group contained DMSO at the corresponding volume to the added RA in treatment groups. (B) RA 100nM concentration. (C) RA 300nM concentration. (D) RA 500nM concentration. In this figure, we can observe that specimens cultured with 500nM RA have a higher number of buds compared to other groups. 
day 2

$\mathrm{FGF} 10+\mathrm{DMSO}+\mathrm{H} / \mathrm{S}$

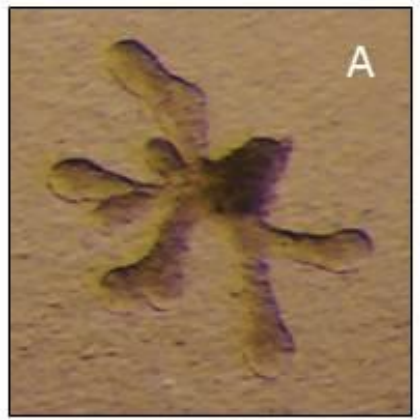

FGF10+ H/S+ RA(500nM)

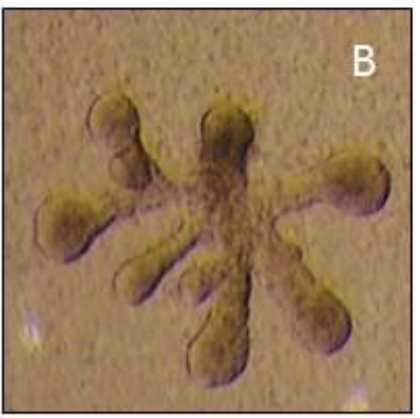

FGF10+ H/S + BMS 5uM

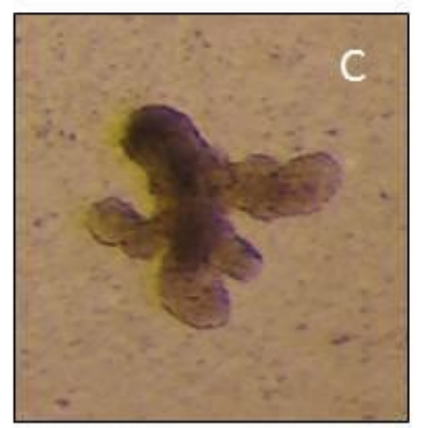

Figure17: Isolated epithelia cultured with addition of retinoic acid or BMS 493 cultured for 2 days. (A) Control group cultured with DMSO in the corresponding volume (B) Treatment group with RA at 500nM concentration. (C) BMS493 at 5uM concentration. There is no significant difference in phenotype between control and RA treatment group. On the other hand, the group treated with BMS493 shows inhibition in growth and less number of branches. 
Table 3: Branch number Control RA and statistical verification

\begin{tabular}{|l|l|l|l|l|l|}
\hline \multicolumn{2}{|l|}{ 1st EXP 11.02.15 } & \multicolumn{2}{l|}{ 2nd EXP 11.09.15 } & \multicolumn{2}{l|}{ 3rd EXP 11.11.15 } \\
\hline Control & RA & Control & RA & Control & RA \\
\hline 5 & 10 & 5 & 6 & 6 & 5 \\
\hline 6 & 7 & 5 & 4 & 6 & 7 \\
\hline 5 & 7 & 9 & 6 & 10 & 6 \\
\hline 9 & 5 & & & & \\
\hline 6 & 7 & & & & \\
\hline 5 & 9 & & & & \\
\hline 7 & & & & & \\
\hline average & average & average & average & average & average \\
\hline 6.142857 & 7.5 & 6.333333 & 5.333333 & 7.333333 & 6 \\
\hline
\end{tabular}

t-Test: Two-Sample Assuming Unequal Variances

\begin{tabular}{lll}
\hline & Control & $R A$ \\
\hline Mean & 6.603175 & 6.277778 \\
Variance & 0.408919 & 1.231481 \\
Observations & 3 & 3 \\
$\begin{array}{l}\text { Hypothesized Mean } \\
\text { Difference }\end{array}$ & 0 & \\
df & 3 & \\
t Stat & 0.440047 & \\
$\mathrm{P}(\mathrm{T}<=\mathrm{t})$ one-tail & 0.344839 & \\
t Critical one-tail & 2.353363 & \\
$\mathrm{P}(\mathrm{T}<=\mathrm{t})$ two-tail & 0.689677 & \\
$\mathrm{t}$ Critical two-tail & 3.182446 & \\
\hline
\end{tabular}




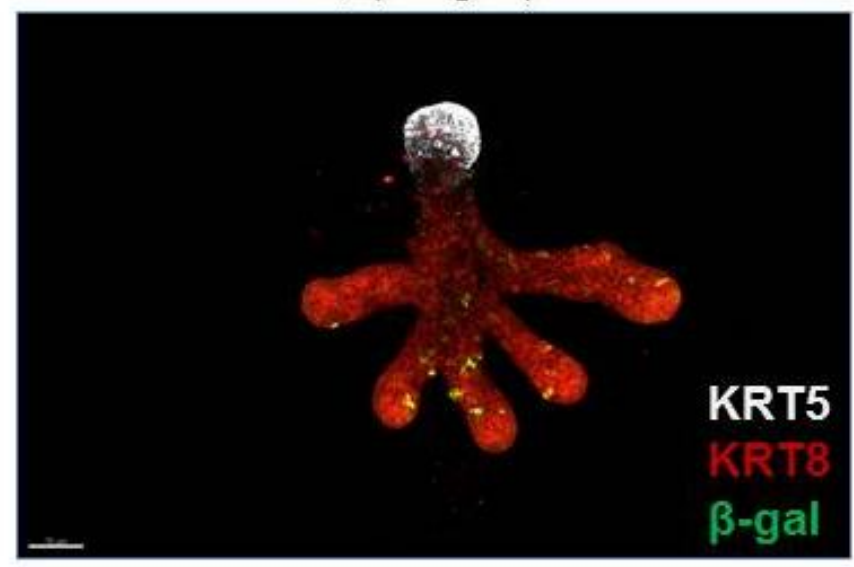

FGF10+ H/S + $\mathrm{RA}(500 \mathrm{nM})$

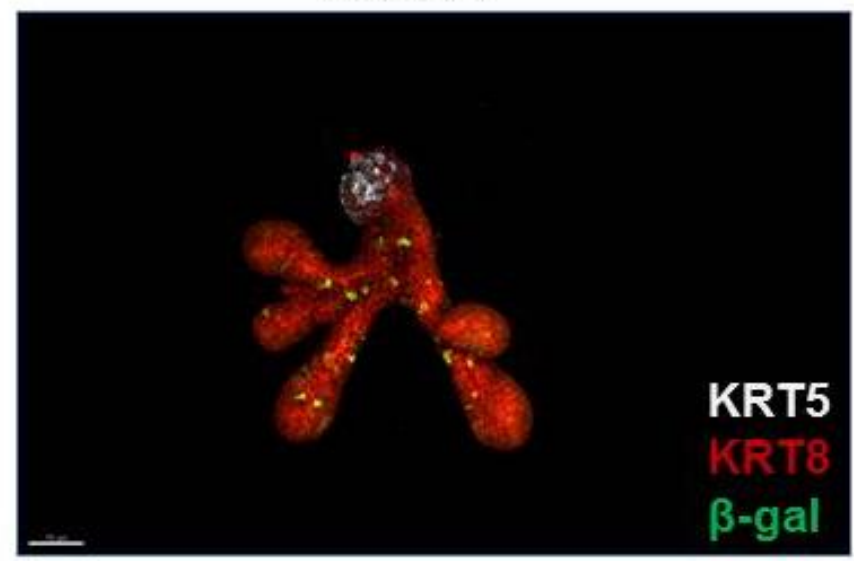

Figure18: Immunostaining of ER cultured for 2 days on control medium, or medium containing $500 \mathrm{nM}$ RA. With these experiment conditions, no difference in expression of RA was detected. We speculate the experiment was compromised by technical difficulties related to the labilty of RA, which breaks down when exposed to light or oxygen. 


\subsection{Block of RA signaling coordinately upregulates expression of $\mathrm{Krt5}$ and Krt14}

In order to accurately quantify the level of $K r t 5$ upregulation when RA signaling was blocked, and to determine if the upregulation occurred at the level of gene transcription, we performed qPCR on ER cultured on BMS 493 or control medium. ER were cultured for 48 hours followed by RNA purification and QPCR analysis to assess the relative expression level of $K r t 5$ and other genes. Analysis of qPCR data revealed that $K r t 5$ mRNA was $\geq 24$-fold higher in BMS 493-treated ER relative to controls, $\mathrm{N}=3$ independent culture experiments with 6-8 ER/condition $\times 6$ technical qPCR replicates $(p=0.000002)$ (Fig. 19). These data demonstrate that the elevated level of KRT5 protein observed by immunostaining (Fig. 15) of control and BMS 493 treated specimens results from a dramatic and significant upregulation of $K r t 5$ mRNA expression.

We investigated also whether blocking RA signal with BMS 493 altered expression of $K r t 5$ specifically, or if an expression of other members of other members of the keratin family were likewise impacted. RNA from cultured ER were subjected to qPCR analysis for Krt14, the dimerization partner for $K r t 5$ in basal epithelial cells and for Krt8 and Krt19, which are present in luminal epithelial layers. The qPCR analysis revealed that $K r t 14$ was upregulated $\geq$ 8-fold in BMS 493-treated ER specimens relative to controls, $\mathrm{N}=3$ independent culture experiments with 6-8 ER/condition $\times 3$ technical qPCR replicates $(p \leq$ 0.03). No significant change in expression of $K r t 8$ or $K r t 19$ was observed. These data demonstrate that inhibition of RA signaling coordinately upregulates 
expression of the two basal epithelial keratins $K r t 5$ and $K r t 14$. Inhibition of RA signaling specifically impacts expression $K r t 5$ and $K r t 14$, and does not generally alter expression of other keratin family genes. Thus, RA signaling negatively regulates expression $K r t 5$ and $K r t 14$. 
Fig. 5

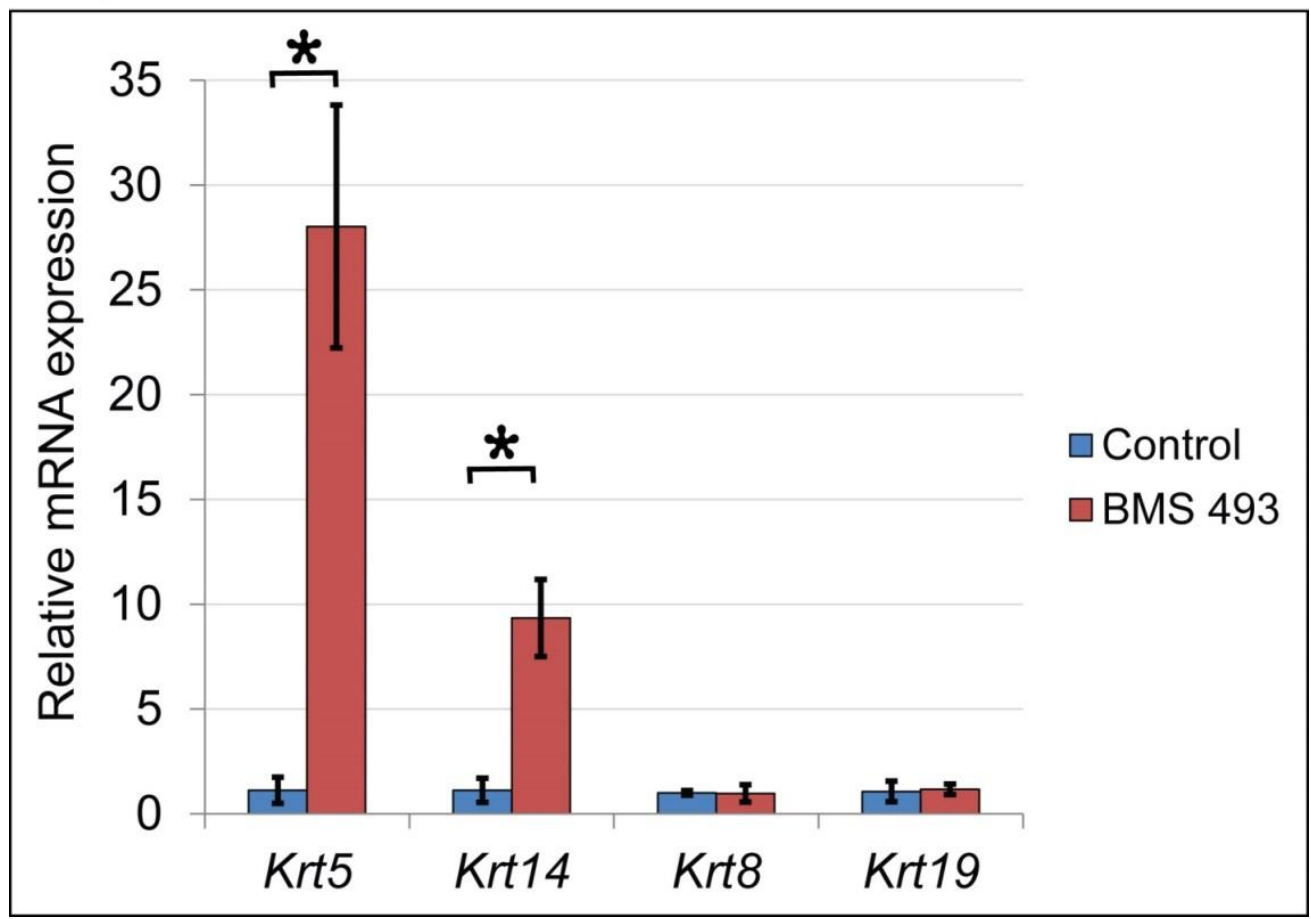

Figure 19. Inhibition of RA signaling upregulates expression of $K r t 5$ and Krt14 mRNA. Quantitation of gene expression by qPCR demonstrates that Krt5 and its dimerization partner $\mathrm{Krt14}$ are upregulated by inhibition of RA signaling with BMS 493. Krt5 is upregulated $\geq 24$ fold $(p=0.000002)$ and $K r t 14$ is upregulated $\geq 8$ fold $(p \leq 0.03)$ in ER grown in BMS 493 relative to controls. No significant change in expression is observed for keratins Krt8 or Krt19. Data represent averages for 3 independent culture experiments with 6-8 ER/condition. For Krt5 each cDNA sample was run as 6 technical qPCR replicates, for all others, each sample was run as 3 technical replicates. Error bars represent standard deviations. 


\subsection{Stem cell marker $K i t$ is regulated inversely to $K r t 5 / K r t 14$ by RA signaling}

Because $K r t 5$ and $K r t 14$ have been implicated as markers of stem cells or progenitor cells in developing salivary gland epithelia, we investigated whether inhibition of RA signaling coordinately regulated stem cell genes in conjunction with Krt5 and Krt14. Expression of Sox2, cMyc, Klf4, and Kit were assessed by QPCR for control and BMS -treated ER. No significant difference was observed for Sox2, cMyc or Klf4 between control and BMS 493 treated specimens (Fig. 20). Thus, the stem cell markers Sox2, cMyc and KIf4 are not coordinately upregulated with $K r t 5 / K r t 14$ by inhibition of RA signaling.

While expression of Sox2, cMyc or KIf4, was not significantly changed by BMS 493 treatment, expression of the stem cell marker Kit was significantly altered by inhibition of RA signaling. Expression of Kit was reduced $\geq 16$-fold in BMS 493-treated ER relative to ER grown on control medium, $\mathrm{N}=3$ independent culture experiments with 6-8 ER/condition $\times 3$ technical qPCR replicates, $p \leq 0.0007$, (Fig. 20). These data demonstrate that treatment with the RA signal inhibitor BMS 493 represses Kit expression in salivary epithelial cells, indicating that RA signaling positively regulates Kit expression. Moreover, the data show that the stem cell gene Kit is regulated inversely to $K r t 5 / K r t 14$ by inhibition of RA signaling in this context. 
Fig. 6

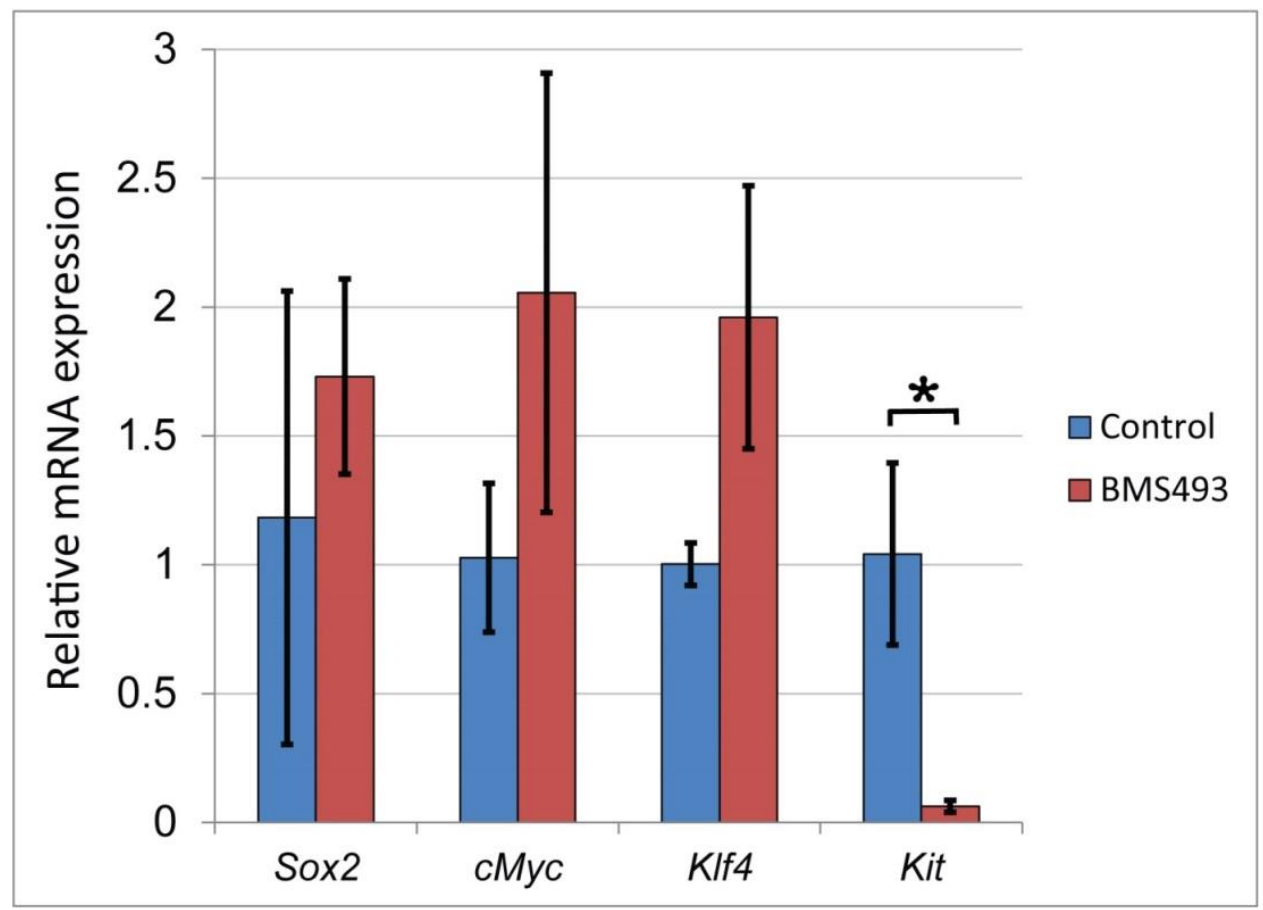

Figure 20. Inhibition of RA signaling downregulates expression of stem cell marker Kit. Expression of genes associated with stem cell character in ER cultured on BMS 493 or control medium was analyzed by qPCR. Sox2, cMYC, and KIf4 were not significantly different between control or treated specimens. Kit was $\geq 16$-fold downregulated in ER cultured on BMS 493 relative to ER cultured on control medium ( $p=0.0007)$. Data represent averages for 3 independent culture experiments with 6-8 ER/condition, each sample was run as 3 technical replicates. 


\subsection{Bioinformatic analysis of RAR and RXR binding motifs near keratin and stem cell genes}

Because we saw some changes in expression of salivary keratins and stem cell genes, we sought to determine if RAR binding motif were present near these

genes. To address this question we used Motifmap(http://motifmap.ics.uci.edu/) database search engine to search for RAR and RXR binding motifs throughout the mouse genome. Of all genes that we assessed using qPCR only near Myc gene, there is a sequence that can be a possible site of RXR transcription factor binding. Using this database search engine we did not found binding sites for other genes that we analyzed where RAR or RXR transcription factors can bind. 


\section{CHAPTER 4}

\section{DISCUSSION}

We have previously demonstrated that Vitamin A metabolism and RA signaling is important for developmental growth and branching morphogenesis of SMG epithelium (Wright et al., 2015). For this study we extend our initial analysis, demonstrating that canonical RA signaling occurs in multiple tissues of the developing SMG, including epithelium, neurons, and non-neuronal mesenchyme (Fig. 3 A-D). By inhibiting RA signaling in isolated ER in a culture we show here that RA signaling regulates epithelial branching morphogenesis by direct action in epithelial cells (Fig.13 B-D). Moreover, we demonstrate that RA signaling within epithelial cells is required to promote or maintain signaling by the essential FGF10 signaling pathway (Fig. $13 \mathrm{E}$ ). We show also that two important cytokeratins $K r t 5$ and $K r t 14$ are significantly upregulated by inhibition of RA signaling in culture (Fig. 15 E-H and Fig. 19). Importantly, we show inhibition of RA signaling in cultured embryonic salivary epithelium reduces expression of the stem cell marker Kit (Fig.20) Our data demonstrate that upregulation of Krt5 and Krt14 by inhibition of RA signaling correlates inversely with expression of the stem cell gene Kit, demonstrating that $K r t 5$ and $K r t 14$ expression is independent of stem cell character in this context. 
We show here, by immunostain analysis of sectioned embryos, that RA signaling occurs within multiple tissues of the developing SMG, being present in the epithelium, mesenchyme, and neurons. Within the epithelium of E13.5 pseudoglandular SMG RA signaling is active, but not in all cells. Instead, 10\% of cells distributed in a mosaic pattern are positive for RA signal. RA signal positive cells are present in both the basal and supra-basal compartments of the epithelium, in endbuds and ducts (Fig. 3 A-B, Fig. 5 A). Such analyses do not reveal whether the pattern of RA signaling is static or dynamic within E13.5 SMG epithelium. If static, then the $10 \%$ RA signal positive cells may have a unique identity from their neighboring epithelial cells. If, on the other hand, RA signaling is dynamic in this tissue, as it is in other developmental contexts (Bok et al., 2011; Schilling et al., 2012), it is possible that all E13.5 SMG epithelial cells are similar with respect to RA signaling, being different only in the timing of RA signal activity.

We also show that salivary gland that is cultured for a prolonged period of time on media lacking retinoids can maintain RA signaling necessary for its development.(Figure4) We demonstrate that signal persists in culture for up to 5 days(Figure4A-D). Therefore, we can suggest that SMG that was isolated still contain precursors inside and also can produce enzymes required for their conversion into active RA. Moreover, we show that as morphogenesis progresses focus of RA signaling shift from epithelial to mesenchymal tissues(Figure\#C-D). It is mainly expressed in tissues adjacent to the main duct where the parasympathetic ganglion is positioned. 
We show here, by inhibiting RA signaling in cultured isolated ER with the pan-RAR inhibitor BMS 493, that RA signaling is required directly within SMG epithelium of cultured ER to promote branching morphogenesis (Fig. 5B, Fig. 13 A-D). These data raise the possibility that modulation of RA signaling could be utilized in the context of in vitro methods aimed at generating salivary epithelial tissues for transplantation. In addition to its direct action in the epithelium, RA signaling may also influence epithelium development indirectly via action in nerve or mesenchyme.

It is well established that growth and branching of salivary epithelial tissues is dependent upon signaling by the growth factor FGF10 (De Moerlooze et al., 2000; Entesarian et al., 2005; Milunsky et al., 2006; Ohuchi et al., 2000; Rohmann et al., 2006; Wells et al., 2013). Here we report that RA signal inhibition is associated with a reduction in FGF10 activity, as measured by expression of the FGF10 target gene Etv5. These data demonstrate that RA positively regulates the essential FGF10 pathway during growth and branching of salivary epithelium in culture.

Interactions between RA signaling and FGF signaling pathways occur in many tissues during embryonic morphogenesis (Diez del Corral et al., 2003; Dubrulle and Pourquie, 2004; Moreno and Kintner, 2004; Shen et al., 2007; Sirbu and Duester, 2006; Sorrell and Waxman, 2011; Wilson et al., 2009). In some cases RA and FGF pathways work together positively in the same direction, in other cases, RA and FGF pathways antagonize each other. Positive regulation of the FGF10 pathway by RA signaling occurs during initiation of lung 
development (Chen et al., 2010; Chen et al., 2007; Desai et al., 2004). The data reported here identify a new developmental context in which RA signaling positively regulates FGF10 activity.

We demonstrate that RA signaling is important for cell proliferation in the epithelium of SMG. We show the inhibition of retinoid signaling in isolated epithelia leads to decreased expression of Mki67 and Top2a, two markers of proliferation. RA can directly influence p38 MAP kinase (Al Tanoury et al, 2013), an enzyme that has mitogenic activity (Zarubin et al. 2005). Therefore, it is possible that RA influences proliferation by the p38 MAPK pathway. However, it has been thought that FGF10 signaling is the main driver of mitotic activity in developing SMG epithelium (Steinberg et al. 2005). FGF10 signaling influences proliferation through a different kinase cascade, the MAPK/ERK pathway. Therefore, it is possible that RA signaling influences proliferation either by the influence the p38MAPK pathway, or by stimulating the MAPK/ERK pathway downstream of FGF10 and FGF2Rb, or both.

Our result showing that RA signaling is necessary for expression of Etv5, which is a downstream target of FGF10, suggests that RA may work through the FGF10 pathway. In this particular study, we cannot draw final conclusions on this topic. Further experiments are required in order to answer this question. For example, it would be interesting to assess expression of p38 downstream targets in order to verify whether the change in proliferation is associated with an alteration in this pathway. On the other hand, it would be intriguing to identify 
whether regulation of Etv5 by RA occurs by way of the MAPK/ERK or any other downstream target of FGF10 signaling.

Identifying and understanding stem cells or progenitor cells of salivary epithelium is an important research goal. In many studies of salivary epithelium, the basal epithelial cytokeratin KRT5 has been interpreted as a marker of stem cells or progenitor cells (Knox et al., 2010; Lombaert et al., 2011). Here we show Krt5 is negatively regulated by RA signaling in cultured ER (Fig. 15 E-H, Fig. 19). Inhibition of RA signaling results in elevated KRT5 in basal epithelial cells of all ducts and endbuds (Fig. $15 \mathrm{E}-\mathrm{H}, \mathrm{K}$ ). The near ubiquity of the KRT5 response to blockage of RA signaling is somewhat surprising given that RA signaling is normally active in only a fraction of the cells (Fig. $5 \mathrm{~B}$, Fig. $15 \mathrm{C}$ ). The widespread KRT5 elevation resulting from blockage of RA may suggest that the subset of cells that lose their active RA signaling influence their neighbors. Alternatively, if RA signaling is dynamic and occurs in all epithelial cells over time, then inhibition of RA signaling could impact all cells of the epithelium by direct action in each cell.

By qPCR analysis of cultured ER specimens, we demonstrated that the negative regulation of $K r t 5$ by RA signaling occurs at the level of gene transcription. The increase in Krt5 expression following inhibition of RA signal is consistent with previous in vitro transcription studies demonstrating negative regulation of $\mathrm{Krt5}$ by liganded RAR (Ohtsuki et al., 1992; Radoja et al., 1997; Tomic-Canic et al., 
1996). Here we identify embryonic salivary epithelium as a new biological context for RA regulation of $K r t 5$ transcription. Expression of $K r t 5$ has been shown to be downregulated by FGF signaling in whole gland culture (Knosp et al., 2015), indicating FGF negatively regulates $K r t 5$ expression. Consistent with the previous observation, we show that reduced FGF10 signaling, in this case, owing to inhibition of RA signaling, results in elevated expression of Krt5.

BMS 493 is defined as a pan-RAR inverse agonist because it enhances interactions of RAR with the nuclear receptor corepressor NcoR (Germain et al., 2009). In that context, BMS 493 inhibits expression of RA regulated genes. Here we identify a novel action of BMS 493 showing that this RAR inverse agonist can cause activation of a gene. We speculate that $K r t 5$ gene activation by BMS 493 could possibly result from context dependent enhancement of interactions between RAR and coactivators, or disruption of interactions with ligand-dependent corepressors such as TNIP, RIF1, Trim24, PRAME, LCoR, or RIP140 (Epping et al., 2005; Gurevich and Aneskievich, 2009; Heim et al., 2007; Hu et al., 2004; Khetchoumian et al., 2007; Li et al., 2007; White et al., 2004).

KRT5 functions as a component of intermediate filaments in combination with its hetero-dimerization partner KRT14 (Coulombe and Fuchs, 1990; Lee and Coulombe, 2009; Lee et al., 2012). The two keratins are co-expressed in the basal layer of many epithelial tissues (Moll et al., 1982; Purkis et al., 1990). Together, KRT5 and KRT14 have been implicated as marking stem cells in embryonic salivary glands and other epithelial tissues (Lombaert and Hoffman, 2010; Rock et al., 2009). The two keratins are transcriptionally co-regulated. 
Reduction of Krt14 by RNA interference in cultured epithelial cells results in downregulation of Krt5 (Alam et al., 2011). Our data reported here indicate that one mechanism of transcriptional co-regulation of $K r t 5, K r t 14$ is RA signaling (Fig. 19).

Importantly, we show here that RA signaling does not coordinately regulate expression of stem cells markers in conjunction with $K r t 5$ and $K r t 14$ (Fig. 20). Treatment with the RA signaling inhibitor BMS 493, which upregulates Krt5 and $K r t 14$, causes no significant change in expression of Sox2, cMyc or Klf4, and results in significant downregulation of Kit (Fig. 20). These data demonstrate that Krt5 and Krt14 are regulated independently of progenitor cell character by RA signaling. They also demonstrate that expression of $K r t 5$ or Krt14 on their own are not reliable markers of salivary epithelial progenitor identity.

One of the main obstacles in this study was obtaining embryonic SMG specimens at precise gestational stages. We observed that the stage of SMG within 1 litter can vary from E13.0 to E14.0. This created inconsistency between specimens. Importantly, older ER specimens were more capable of growth and branching after separation from mesenchyme than younger ones. Older specimens with 4-6 buds could develop in culture to form elaborate structures up to 17 branches and buds. Conversely, younger analogs with 2-3 buds were able to form not more than 5 branches after the same period in culture. We tried to eliminate this problem by randomizing specimens in different groups so both control and treatment groups had equal variation in age. Nonetheless, the variation can affect the results. 
Another caveat for this study is that culturing isolated tissue, on the one hand, allows us to study a particular type of tissue, but, on the other hand, may not represent the in vivo situation. Thus, it would be valuable to perform similar experiments with the whole SMG in order to confirm the results. In addition, it would be interesting to perform in vivo experiments using conditional mutant embryos that lack RA signaling in the glands.

In my opinion, it will be particularly intriguing to identify molecules that are exclusively expressed in RA positive cells. Here we demonstrated that RA signal in developing glands does not occur evenly in all cells of the gland epithelium, but occurs in a mosaic pattern in vivo and in culture. Another important question will be to determine what developmental process is controlled by retinoid signaling. One process that plays a crucial role in SMG development is duct formation with a polarization of luminal epithelium. It will be interesting to determine if molecules important in the process of cell orientation and polarization, such as ZO-1 or aPKC, are regulated by RA signaling.

We have observed that RA signaling occurs in tissues where SMG will develop prior to gland formation. We observe RA signal in mandible epithelium and mesenchyme, appearing at E10.5 (Wright et al. 2015). Thus, RA signal is present during very early stages of SMG, when epithelium undergoes drastic morphological change as the epithelium invaginates and starts the formation of the gland. The drastic morphological changes in epithelium may involve changes in expression of genes involved in cell motility and migration, or epithelial-tomesenchymal transition (EMT). Such genes include Zeb1, Twist1, and Snai1. It 
would be interesting to determine if these EMT genes are influenced by RA signaling in early gland development.

This study was focused on the development of SMG epithelium. However, during SMG formation, cells of the nerve ganglion play an equally important role gland morphogenesis. Because we demonstrate here that there is robust RA signal in parasympathetic nerve ganglion cells in the developing SMG, it will be valuable to determine if RA signaling is important for nerve development. Future studies could examine if RA signaling is important for proliferation of nerve cells, or maybe for differentiation of neurons. 


\section{CHAPTER 5}

\section{SUMMARY AND CONCLUSIONS}

Many people suffer from salivary gland dysfunction and there is a need to understand signals that regulate development of salivary gland epithelium. This study has demonstrated that RA signaling is required for proper development of SMG epithelium. We showed that RA is required for epithelial cell proliferation and branching and that RA controls the expression of $K r t 5$ and $K r t 14$. Importantly, we showed that expression of $K r t 5$ and $K r t 14$ is not necessarily associated with stem cell profile. Our data may be useful for translational researchers designing approaches for salivary gland bioengineering. 


\section{REFERENCES}

Al Tanoury Z, Piskunov A, Rochette-Egly C. 2013. Vitamin A and retinoid signaling: genomic and nongenomic effects: Thematic Review Series: FatSoluble Vitamins: Vitamin A. Journal of Lipid Research 54:1761-1775.

Alam, H., Sehgal, L., Kundu, S.T., Dalal, S.N., and Vaidya, M.M. (2011). Novel function of keratins 5 and 14 in proliferation and differentiation of stratified epithelial cells. Mol Biol Cell 22, 4068-4078.

Altekruse, S. F., Kosary, C. L., Krapcho, M., Neyman, N., Aminou, R., Waldron, W., ... \& Mariotto, A. (2010). SEER cancer statistics review, 1975-2007.

Bethesda, MD: National Cancer Institute, 7.

Aure, M.H., Konieczny, S.F., and Ovitt, C.E. (2015). Salivary gland homeostasis is maintained through acinar cell self-duplication. Dev Cell 33, 231-237.

Baldini, C., Talarico, R., Tzioufas, A. G., \& Bombardieri, S. (2012). Classification criteria for Sjogren's syndrome: a critical review. Journal of autoimmunity, 39(1), $9-14$.

Bok, J., Raft, S., Kong, K.A., Koo, S.K., Drager, U.C., and Wu, D.K. (2011).

Transient retinoic acid signaling confers anterior-posterior polarity to the inner ear. Proc Natl Acad Sci U S A 108, 161-166.

Broudy, V.C. (1997). Stem cell factor and hematopoiesis. Blood 90, 1345-1364. 
Chen, F., Cao, Y., Qian, J., Shao, F., Niederreither, K., and Cardoso, W.V. (2010). A retinoic acid-dependent network in the foregut controls formation of the mouse lung primordium. J Clin Invest 120, 2040-2048.

Chen, F., Desai, T.J., Qian, J., Niederreither, K., Lu, J., and Cardoso, W.V. (2007). Inhibition of Tgf beta signaling by endogenous retinoic acid is essential for primary lung bud induction. Development 134, 2969-2979.

Clagett-Dame, M., and Knutson, D. (2011). Vitamin a in reproduction and development. Nutrients 3, 385-428.

Colopy, S.A., Bjorling, D.E., Mulligan, W.A., and Bushman, W. (2014). A

Population of Progenitor Cells in the Basal and Intermediate Layers of the Murine Bladder Urothelium Contributes to Urothelial Development and Regeneration. Developmental dynamics : an official publication of the American Association of Anatomists 243, 988-998.

Coulombe, P.A., and Fuchs, E. (1990). Elucidating the early stages of keratin filament assembly. J Cell Biol 111, 153-169.

De Moerlooze, L., Spencer-Dene, B., Revest, J., Hajihosseini, M., Rosewell, I., and Dickson, C. (2000). An important role for the IIllb isoform of fibroblast growth factor receptor 2 (FGFR2) in mesenchymal-epithelial signalling during mouse organogenesis. Development 127, 483-492.

Desai, T.J., Malpel, S., Flentke, G.R., Smith, S.M., and Cardoso, W.V. (2004). Retinoic acid selectively regulates Fgf10 expression and maintains cell identity in the prospective lung field of the developing foregut. Dev Biol 273, 402-415. 
Diez del Corral, R., Olivera-Martinez, I., Goriely, A., Gale, E., Maden, M., and Storey, K. (2003). Opposing FGF and retinoid pathways control ventral neural pattern, neuronal differentiation, and segmentation during body axis extension. Neuron 40, 65-79.

Dubrulle, J., and Pourquie, O. (2004). Coupling segmentation to axis formation. Development 131, 5783-5793.

Entesarian, M., Matsson, H., Klar, J., Bergendal, B., Olson, L., Arakaki, R., Hayashi, Y., Ohuchi, H., Falahat, B., Bolstad, A.I., et al. (2005). Mutations in the gene encoding fibroblast growth factor 10 are associated with aplasia of lacrimal and salivary glands. Nat Genet 37, 125-128.

Epping, M.T., Wang, L., Edel, M.J., Carlee, L., Hernandez, M., and Bernards, R. (2005). The human tumor antigen PRAME is a dominant repressor of retinoic acid receptor signaling. Cell 122, 835-847.

Firnberg, N., and Neubuser, A. (2002). FGF signaling regulates expression of Tbx2, Erm, Pea3, and Pax3 in the early nasal region. Dev Biol 247, 237-250. Germain, P., Gaudon, C., Pogenberg, V., Sanglier, S., Van Dorsselaer, A., Royer, C.A., Lazar, M.A., Bourguet, W., and Gronemeyer, H. (2009). Differential action on coregulator interaction defines inverse retinoid agonists and neutral antagonists. Chem Biol 16, 479-489.

Goswami PC, Roti Roti JL, Hunt CR. 1996. The cell cycle-coupled expression of topoisomerase Ilalpha during $S$ phase is regulated by mRNA stability and is disrupted by heat shock or ionizing radiation. Mol Cell Biol 16:1500-1508. 
Gurevich, I., and Aneskievich, B.J. (2009). Liganded RAR $\alpha$ and RARy interact with but are repressed by TNIP1. Biochem Biophys Res Commun 389, 409-414. Haugen, A. J., Peen, E., Hulten, B., Johannessen, A. C., Brun, J. G., Halse, A. K., \& Haga, H. J. (2008). Estimation of the prevalence of primary Sjögren's syndrome in two age-different community-based populations using two sets of classification criteria: the Hordaland Health Study. Scandinavian journal of rheumatology, 37(1), 30-34.

Heim, K.C., White, K.A., Deng, D., Tomlinson, C.R., Moore, J.H., Freemantle, S.J., and Spinella, M.J. (2007). Selective repression of retinoic acid target genes by RIP140 during induced tumor cell differentiation of pluripotent human embryonal carcinoma cells. Mol Cancer 6, 57.

Holmberg, K. V., \& Hoffman, M. P. (2014). Anatomy, biogenesis and regeneration of salivary glands. In Saliva: Secretion and Functions (Vol. 24, pp. 1-13). Karger Publishers.

Hu, X., Chen, Y., Farooqui, M., Thomas, M.C., Chiang, C.M., and Wei, L.N. (2004). Suppressive effect of receptor-interacting protein 140 on coregulator binding to retinoic acid receptor complexes, histone-modifying enzyme activity, and gene activation. J Biol Chem 279, 319-325.

Hudson, D.L., Guy, A.T., Fry, P., O'Hare, M.J., Watt, F.M., and Masters, J.R.W. (2001). Epithelial Cell Differentiation Pathways in the Human Prostate: Identification of Intermediate Phenotypes by Keratin Expression. J Histochem Cytochem 49, 271-278. 
Ishida S, Huang E, Zuzan H, Spang R, Leone G, West M, Nevins JR. 2001. Role for E2F in control of both DNA replication and mitotic functions as revealed from DNA microarray analysis. Mol Cell Biol 21:4684-4699.

Jaskoll, T., Abichaker, G., Witcher, D., Sala, F., Bellusci, S., Hajihosseini, M., and Melnick, M. (2005). FGF10/FGFR2b signaling plays essential roles during in vivo embryonic submandibular salivary gland morphogenesis. BMC Dev Biol 5, 11 . Jho, S.H., Radoja, N., Im, M.J., and Tomic-Canic, M. (2001). Negative response elements in keratin genes mediate transcriptional repression and the cross-talk among nuclear receptors. J Biol Chem 276, 45914-45920.

Joraku, A., Sullivan, C. A., Yoo, J., \& Atala, A. (2007). In-vitro reconstitution of three-dimensional human salivary gland tissue structures. Differentiation, 75(4), 318-324.

Khetchoumian, K., Teletin, M., Tisserand, J., Mark, M., Herquel, B., Ignat, M., Zucman-Rossi, J., Cammas, F., Lerouge, T., Thibault, C., et al. (2007). Loss of Trim24 (Tif1[alpha]) gene function confers oncogenic activity to retinoic acid receptor alpha. Nat Genet 39, 1500-1506.

Knosp, W.M., Knox, S.M., and Hoffman, M.P. (2012). Salivary gland organogenesis. Wiley Interdisciplinary Reviews: Developmental Biology 1, 69-82. Knosp, W.M., Knox, S.M., Lombaert, I.M., Haddox, C.L., Patel, V.N., and Hoffman, M.P. (2015). Submandibular parasympathetic gangliogenesis requires sprouty-dependent Wnt signals from epithelial progenitors. Dev Cell 32, 667-677. 
Knox, S.M., Lombaert, I.M.A., Reed, X., Vitale-Cross, L., Gutkind, J.S., and Hoffman, M.P. (2010). Parasympathetic Innervation Maintains Epithelial Progenitor Cells During Salivary Organogenesis. Science 329, 1645-1647. Kratochwil, K. (1969). Organ specificity in mesenchymal induction demonstrated in the embryonic development of the mammary gland of the mouse. Dev Biol 20, 46-71.

Lee, C.H., and Coulombe, P.A. (2009). Self-organization of keratin intermediate filaments into cross-linked networks. J Cell Biol 186, 409-421.

Lee, C.H., Kim, M.S., Chung, B.M., Leahy, D.J., and Coulombe, P.A. (2012).

Structural basis for heteromeric assembly and perinuclear organization of keratin filaments. Nat Struct Mol Biol 19, 707-715.

Li, H.J., Haque, Z.K., Chen, A., and Mendelsohn, M. (2007). RIF-1, a novel nuclear receptor corepressor that associates with the nuclear matrix. J Cell Biochem 102, 1021-1035.

Liu, C. C., Xia, R., Guadagnolo, A., Cormier, J. N., \& Du, X. L. (2011). Risk of xerostomia in association with the receipt of radiation therapy in older patients with head and neck cancer. American journal of therapeutics, 18(3), 206-215. Liu, Y., Jiang, H., Crawford, H.C., and Hogan, B.L. (2003). Role for ETS domain transcription factors Pea3/Erm in mouse lung development. Dev Biol 261, 10-24. Liu, Z., Hu, Q., and Rosenfeld, M.G. (2014). Complexity of the RAR-mediated transcriptional regulatory programs. Subcell Biochem 70, 203-225. 
Livak, K.J., and Schmittgen, T.D. (2001). Analysis of relative gene expression data using real-time quantitative PCR and the 2(-Delta Delta C(T)) Method. Methods 25, 402-408.

Lombaert, I.M.A., Brunsting, J.F., Wierenga, P.K., Faber, H., Stokman, M.A., Kok, T., Visser, W.H., Kampinga, H.H., de Haan, G., and Coppes, R.P. (2008). Rescue of Salivary Gland Function after Stem Cell Transplantation in Irradiated Glands. PLoS ONE 3, e2063.

Lombaert, I.M.A., and Hoffman, M.P. (2010). Epithelial Stem/Progenitor Cells in the Embryonic Mouse Submandibular Gland. Frontiers of Oral Biology 14, 90106.

Lombaert, I.M.A., Knox, S.M., and Hoffman, M.P. (2011). Salivary gland progenitor cell biology provides a rationale for therapeutic salivary gland regeneration. Oral Dis 17, 445-449.

Makarenkova, H. P., Hoffman, M. P., Beenken, A., Eliseenkova, A. V., Meech, R., Tsau, C., ... \& Mohammadi, M. (2009). Differential interactions of FGFs with heparan sulfate control gradient formation and branching morphogenesis. Science signaling, 2(88), ra55.

Mark, M., Ghyselinck, N., \& Chambon, P. (2009). Function of retinoic acid receptors during embryonic development. Nucl Recept Signal, 7, e002.

Michos, O., Cebrian, C., Hyink, D., Grieshammer, U., Williams, L., D'Agati, V., Licht, J.D., Martin, G.R., and Costantini, F. (2010). Kidney development in the absence of Gdnf and Spry1 requires Fgf10. PLoS Genet 6, e1000809. 
Milunsky, J.M., Zhao, G., Maher, T.A., Colby, R., and Everman, D.B. (2006). LADD syndrome is caused by FGF10 mutations. Clin Genet 69, 349-354. Moll, R., Franke, W.W., Schiller, D.L., Geiger, B., and Krepler, R. (1982). The catalog of human cytokeratins: patterns of expression in normal epithelia, tumors and cultured cells. Cell 31, 11-24.

Moreno, T.A., and Kintner, C. (2004). Regulation of segmental patterning by retinoic acid signaling during Xenopus somitogenesis. Dev Cell 6, 205-218. Nanduri, L.S., Lombaert, I.M., van der Zwaag, M., Faber, H., Brunsting, J.F., van Os, R.P., and Coppes, R.P. (2013). Salisphere derived c-Kit+ cell transplantation restores tissue homeostasis in irradiated salivary gland. Radiother Oncol 108, 458-463.

Nedvetsky, P.I., Emmerson, E., Finley, J.K., Ettinger, A., Cruz-Pacheco, N., Prochazka, J., Haddox, C.L., Northrup, E., Hodges, C., Mostov, K.E., et al. (2014). Parasympathetic innervation regulates tubulogenesis in the developing salivary gland. Dev Cell 30, 449-462.

Nguyen, T. T., Mui, B., Mehrabzadeh, M., Chea, Y., Chaudhry, Z., Chaudhry, K., \& Tran, S. D. (2013). Regeneration of Tissues of the Oral Complex: Current. J Can Dent Assoc, 79, d1.

Ogawa, M., Matsuzaki, Y., Nishikawa, S., Hayashi, S., Kunisada, T., Sudo, T., Kina, T., Nakauchi, H., and Nishikawa, S. (1991). Expression and function of c-kit in hemopoietic progenitor cells. J Exp Med 174, 63-71. 
Ogawa, M., Oshima, M., Imamura, A., Sekine, Y., Ishida, K., Yamashita, K., ... \& Tsuji, T. (2013). Functional salivary gland regeneration by transplantation of a bioengineered organ germ. Nature communications, 4 .

Ohtsuki, M., Tomic-Canic, M., Freedberg, I.M., and Blumenberg, M. (1992).

Regulation of Epidermal Keratin Expression by Retinoic Acid and Thyroid Hormone. The Journal of Dermatology 19, 774-780.

Ohuchi, H., Hori, Y., Yamasaki, M., Harada, H., Sekine, K., Kato, S., and Itoh, N. (2000). FGF10 Acts as a Major Ligand for FGF Receptor 2 Illb in Mouse MultiOrgan Development. Biochem Biophys Res Commun 277, 643-649.

Patel, V. N., Pineda, D. L., \& Hoffman, M. P. (2016). The function of heparan sulfate during branching morphogenesis. Matrix Biology.

Purkis, P.E., Steel, J.B., Mackenzie, I.C., Nathrath, W.B., Leigh, I.M., and Lane, E.B. (1990). Antibody markers of basal cells in complex epithelia. J Cell Sci 97 ( Pt 1), 39-50.

Radoja, N., Diaz, D.V., Minars, T.J., Freedberg, I.M., Blumenberg, M., and Tomic-Canic, M. (1997). Specific Organization of the Negative Response Elements for Retinoic Acid and Thyroid Hormone Receptors in Keratin Gene Family. J Invest Dermatol 109, 566-572.

Rebustini, I.T., Patel, V.N., Stewart, J.S., Layvey, A., Georges-Labouesse, E., Miner, J.H., and Hoffman, M.P. (2007). Laminin alpha5 is necessary for submandibular gland epithelial morphogenesis and influences FGFR expression through beta1 integrin signaling. Dev Biol 308, 15-29. 
Rock, J.R., Onaitis, M.W., Rawlins, E.L., Lu, Y., Clark, C.P., Xue, Y., Randell, S.H., and Hogan, B.L. (2009). Basal cells as stem cells of the mouse trachea and human airway epithelium. Proc Natl Acad Sci U S A 106, 12771-12775.

Rohmann, E., Brunner, H.G., Kayserili, H., Uyguner, O., Nurnberg, G., Lew, E.D., Dobbie, A., Eswarakumar, V.P., Uzumcu, A., Ulubil-Emeroglu, M., et al. (2006). Mutations in different components of FGF signaling in LADD syndrome. Nat Genet 38, 414-417.

Rossant, J., Zirngibl, R., Cado, D., Shago, M., and Goguere, V. (1991).

Expression of retinoic acid response element-hsp lacZ transgene defines specific domains of transcriptional activity during mouse embryogenesis. Genes Dev 5, 1333-1344.

Schilling, T.F., Nie, Q., and Lander, A.D. (2012). Dynamics and precision in retinoic acid morphogen gradients. Curr Opin Genet Dev 22, 562-569.

Shen, C.N., Marguerie, A., Chien, C.Y., Dickson, C., Slack, J.M., and Tosh, D. (2007). All-trans retinoic acid suppresses exocrine differentiation and branching morphogenesis in the embryonic pancreas. Differentiation 75 .

Sirbu, I.O., and Duester, G. (2006). Retinoic-acid signalling in node ectoderm and posterior neural plate directs left-right patterning of somitic mesoderm. Nat Cell Biol 8, 271-277.

Sorrell, M.R., and Waxman, J.S. (2011). Restraint of Fgf8 signaling by retinoic acid signaling is required for proper heart and forelimb formation. Dev Biol 358, $44-55$. 
Steinberg, Z., Myers, C., Heim, V.M., Lathrop, C.A., Rebustini, I.T., Stewart, J.S., Larsen, M., and Hoffman, M.P. (2005). FGFR2b signaling regulates ex vivo submandibular gland epithelial cell proliferation and branching morphogenesis. Development 132, 1223-1234.

Strömbeck, B., Ekdahl, C., Manthorpe, R., Wikström, I., \& Jacobsson, L. (2000). Health-related quality of life in primary Sjögren's syndrome, rheumatoid arthritis and fibromyalgia compared to normal population data using SF-36. Scandinavian journal of rheumatology, 29(1), 20-28.

Tomic-Canic, M., Day, D., Samuels, H.H., Freedberg, I.M., and Blumenberg, M. (1996). Novel regulation of keratin gene expression by thyroid hormone and retinoid receptors. J Biol Chem 271, 1416-1423.

Tomic, M., Jiang, C.K., Epstein, H.S., Freedberg, I.M., Samuels, H.H., and Blumenberg, M. (1990). Nuclear receptors for retinoic acid and thyroid hormone regulate transcription of keratin genes. Cell Regul 1, 965-973.

Tucker, A.S. (2007). Salivary gland development. Semin Cell Dev Biol 18, 237244.

Vergeer, M. R., Doornaert, P. A., Rietveld, D. H., Leemans, C. R., Slotman, B. J., \& Langendijk, J. A. (2009). Intensity-modulated radiotherapy reduces radiationinduced morbidity and improves health-related quality of life: results of a nonrandomized prospective study using a standardized follow-up program. International Journal of Radiation Oncology* Biology* Physics, 74(1), 1-8. 
Wang, X., Spandidos, A., Wang, H., and Seed, B. (2012). PrimerBank: a PCR primer database for quantitative gene expression analysis, 2012 update. Nucleic Acids Res 40, D1144-D1149.

Wells, K.L., Gaete, M., Matalova, E., Deutsch, D., Rice, D., and Tucker, A.S. (2013). Dynamic relationship of the epithelium and mesenchyme during salivary gland initiation: the role of Fgf10. Biology Open.

White, J.H., Fernandes, I., Mader, S., and Yang, X.J. (2004). Corepressor recruitment by agonist-bound nuclear receptors. Vitam Horm 68, 123-143. Whitfield ML, Sherlock G, Saldanha AJ, Murray JI, Ball CA, Alexander KE, Matese JC, Perou CM, Hurt MM, Brown PO, Botstein D. 2002. Identification of genes periodically expressed in the human cell cycle and their expression in tumors. Mol Biol Cell 13:1977-2000.

Wilson, V., Olivera-Martinez, I., and Storey, K.G. (2009). Stem cells, signals and vertebrate body axis extension. Development 136, 1591-1604.

Wright, D.M., Buenger, D.E., Abashev, T.M., Lindeman, R.P., Ding, J., and Sandell, L.L. (2015). Retinoic acid regulates embryonic development of mammalian submandibular salivary glands. Dev Biol 407, 57-67.

Zarubin, T., \& Jiahuai, H. A. N. (2005). Activation and signaling of the p38 MAP kinase pathway. Cell research, 15(1), 11-18.

Zuo, W., Zhang, T., Wu, D.Z.A., Guan, S.P., Liew, A.-A., Yamamoto, Y., Wang, X., Lim, S.J., Vincent, M., Lessard, M., et al. (2015). p63+Krt5+ distal airway stem cells are essential for lung regeneration. Nature 517, 616-620. 


\title{
CURRICULUM VITAE
}

\author{
NAME: Timur M. Abashev
}

ADDRESS: Dept. of Oral Immunology and Infectious Disease University of Louisville School of Dentistry 501 South Preston Louisville, KY 40202

DOB: Glazov Russian Federation. - May 24, 1991

EDUCATION \& TRAINING:

Doctor of Stomatology., Moscow State Medical Stomatological University 200712

PROFESSIONAL SOCIETIES:

American Association for Dental Research (AADR) Jan 2015 - Ongoing International Association for Dental Research (IADR) Jan 2015 - Ongoing American Student Dental Association (ASDA) February 2015 - Ongoing PRESENTATIONS:

- 2013 Annual Moscow Dental Intern Conference - oral presentation "Clinical case: Surgical treatment of epulis fissuratum using surgical glue", oral presentation. Moscow, Russian Federation. 
- 2015 Research! Louisville - Third Place Dental Student Award, poster presentation. Louisville, USA.

- 2016 March AADR 2016 annual meeting - poster presentation, Los Angeles, USA.

- 2016 April Fifth Annual Craniofacial and Skin Sciences Research Symposium - poster presentation, Cincinnati, USA.

2016 Kentucky Academy of Scinces annual meeting - Retinoic Acid signaling regulates KRT5 independently of stem cell markers in submandibular salivary gland epithelium, oral prestation. Louisville, USA.

\section{PUBLICATIONS:}

Wright, D. M., Buenger, D. E., Abashev, T. M., Lindeman, R. P., Ding, J., \& Sandell, L. L. (2015). Retinoic acid regulates embryonic development of mammalian submandibular salivary glands. Developmental biology, 407(1), 5767.

Abashev, T. M., Metzler, M. A., Wright, D. M., \& Sandell, L. L. (2016). Retinoic Acid signaling regulates Krt5 and Krt14 independently of stem cell markers in submandibular salivary gland epithelium. Developmental Dynamics. 